\title{
Towards regenerated cellulose fibers with high toughness
}

\author{
Kaniz Moriam • Daisuke Sawada - Kaarlo Nieminen • Michael Hummel • \\ Yibo Ma $\cdot$ Marja Rissanen $\cdot$ Herbert Sixta $(\mathbb{D}$
}

Received: 28 May 2021 / Accepted: 2 August 2021/Published online: 22 August 2021

(C) The Author(s) 2021

\begin{abstract}
The production of sustainable and highperformance fabrics requires high mechanical strength of the individual (staple) fibers. Although Ioncell fibers already exhibit higher fiber strength than commercial man-made cellulose fibers or cotton fibers, we further aimed to increase both strength and toughness to gradually approach synthetic fibers in these properties. Decisive factors for the achievable mechanical properties of the fibers were the pulp purity, the cellulose concentration in the spinning solution and length-to-diameter (L/D) ratio of the cylindrical part of the spinneret. The absence of low molecular weight fractions in combination with an increased average molecular weight had the highest impact on the achievement of both high strength and toughness. Using a spinneret with a high L/D ratio, it was possible to spin Ioncell fibers with a tensile
\end{abstract}

strength of $925 \mathrm{MPa}(61.5 \mathrm{cN} / \mathrm{tex})$ and a modulus of toughness of $83.3 \mathrm{MPa}(55.5 \mathrm{~J} / \mathrm{g})$. According to a fluid dynamic simulation, uniformly longer molecular cellulose chains in combination with a longer cylindrical capillary promoted an effective alignment of the cellulose molecules inside the spinneret capillary before entering the airgap, thus creating the conditions for a simultaneous increase in tensile strength and elongation i.e. toughness of the fiber. Mechanistically, high fiber toughness is caused by the structural parameters in longitudinal direction, in particular by a higher tilt angle, a longer periodicity of the lamellar plane and lower micro void orientation. In summary, we have developed lyocell-type fibers with high strength and toughness, which can potentially be used as a surrogate for synthetic fibers.

Supplementary Information The online version contains supplementary material available at https://doi.org/10.1007/ s10570-021-04134-9.

K. Moriam · D. Sawada $\cdot$ K. Nieminen ·

M. Hummel · Y. Ma · M. Rissanen · H. Sixta ( $₫)$

Department of Bioproducts and Biosystems, Aalto University, P.O Box 16300, 00076 Aalto Espoo, Finland

e-mail: herbert.sixta@aalto.fi 


\section{Graphic abstract}
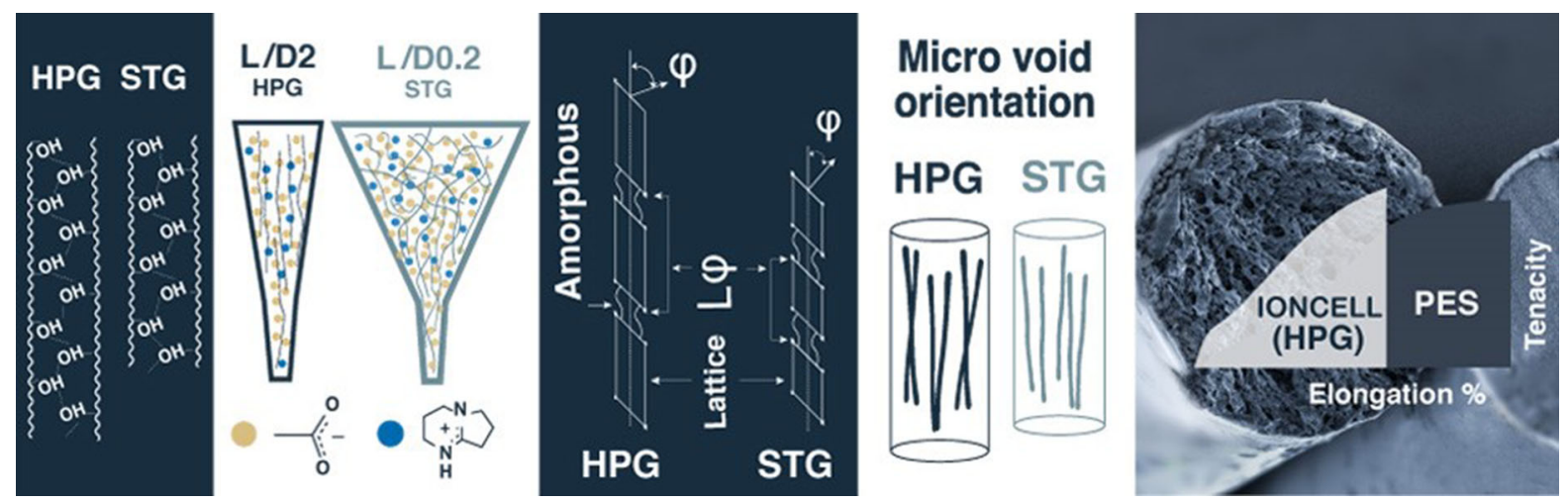

Keywords High strength cellulose fibers · Tough cellulose fiber - Ioncell technology · Ionic liquid · Spinneret capillary

\section{Introduction}

Due to the high toughness coupled with good mechanical, chemical and physical properties, synthetic fibers are widely used in common and technical textiles such as sportswear and work wear. However, previous findings demonstrated that those synthetic fibers are the major sources of microplastics (Acharya et al. 2021). A study showed that the laundering of $6 \mathrm{~kg}$ of synthetic textiles such as polyester-based clothes release approximately 140-730 thousand fibers in every single wash (Napper and Thompson 2016). Another study reported that $8.2-93$ billion microplastic particles and synthetic fibers are discharged per year from the wastewater treatment plant in Germany (Essel et al. 2015). These microplastics contaminate land areas (Zubris and Richards 2005), impact various organisms (Huerta Lwanga et al. 2016), affect the marine environment (Salvador Cesa et al. 2017), enter the food chain (Abihssira-García et al. 2020; Zhang et al. 2021) and consequently affect the human health (Ramsperger et al. 2020; Sana et al. 2020). Considering biodegradability and the ecofriendliness, man-made cellulose fibers could replace at least a certain share of the currently used synthetic fibers. However, in order to convert cellulose a viable substitute-cellulose fibers need to be modified so that their properties match the requirements for above mentioned technical applications. In particular, toughness, the integral of the area of the stress-strain curve, has so far been limited for man-made cellulose fibers (MMCFs). Commercially available cellulose fibers with high tenacity typically have a low elongation and vice versa (Sixta et al. 2015). Further improvements in MMCFs are needed to simultaneously increase the tenacity, and elongation - and consequently increase toughness values.

The increasing importance of cellulosic fibers is reflected in their production volumes. While the global growth of textile fibers in 2019 rose by only $3.4 \%$ to an annual volume of 113.5 million tons, the growth of regenerated cellulose fibers comprising viscose and Lyocell fibers amounted to $7.5 \%$ in the same period and reached a total of 6.0 million tons of staple fibers and 0.34 million tons of filament fibers (The fiber year survey 2019, 2020). Despite the contentious use of carbon disulphide, the incomplete recovery of the sulphur components and the huge amounts of salts generated (e.g. Glauber's salt) and emitted into the environment, the viscose fiber process is by far the dominant process in the production of man-made cellulose fibers (MMCFs) and will remain so in the coming decades. One of the major reasons is that the viscose fiber process enables the production of textile and technical fibers with a broad spectrum of properties that currently cannot be matched by the Lyocell process.

Since the viscose process does not comply with the strictest environmental regulations despite extensive optimization, alternative processes for the production 
of regenerated cellulose fibers have been sought since the 1960s. The Lyocell process has emerged as the only successful alternative process to viscose to date (Guo et al. 2021). Johnson of Eastman Kodak is credited with using NMMO as a direct solvent to produce highly concentrated cellulose solutions (Johnson 1969). Akzona Inc. was pioneering the development of the dry-jet wet spinning process using NMMO monohydrate (McCorsley 1978).

Courtauld and Lenzing share the recognition for the development of the Lyocell fiber process to commercial readiness independent of each other. Today Lenzing is by far the dominant manufacturer of Lyocell fibers with a production of more than $250 \mathrm{kt}$ in 2018 at four sites. The Tencel ${ }^{\mathrm{TM}}$ fibers produced today are very mature and exhibit very good textile mechanical properties $(37 \mathrm{cN} /$ tex conditioned tenacity and $15.6 \%$ elongation; $33 \mathrm{cN} /$ tex wet tenacity and $18.4 \%$ wet elongation, which are superior to comparable viscose fibers (e.g. Lenzing ${ }^{\mathrm{TM}}$ modal). However, no commercially available Lyocell fiber currently achieves the strength potential and in particular the toughness modulus and high fatigue strength of a Super 3 cord viscose fiber. Super 3 cord exhibits both a high tensile strength and the highest toughness and fatigue strength of all regenerated cellulose fibers produced today. A conditioned tensile strength of $750 \mathrm{MPa}(50 \mathrm{cN} /$ tex $)$ at an elongation at break of $17 \%$ and thus a modulus of toughness of $74 \mathrm{MPa}$ was measured from a current sample of a Super 3 cord fiber (Von Bucher 1968). The fiber structure is very finetextured and homogeneous, which enables a more even distribution of the applied load than with other viscose fibers. Thus, the extensibilities are high because of the numerous small movements possible in the amorphous regions when stress is applied and because the structure can accommodate small segment slippage leading to increased ordering effects. Tenacities are also high because individual molecules can pass through several crystallites giving a cooperative effect and, because of the finer texture, the higher orientation is not accompanied by an increase in modulus (which only amounted to $12 \mathrm{GPa}$ ) and a decrease in extensibility. In addition, the use of highpurity wood pulp (alpha cellulose $>98 \%$ ) with a higher average DP (intrinsic viscosity approx. $600 \mathrm{~mL} / \mathrm{g}$ ) is essential in order to achieve these excellent mechanical properties. The Super 3 cord fiber belongs to the all-skin fibers that have a lower water retention, but higher moisture regains than regular viscose fibers. The latter is explained by an increased number of hydroxyl groups available for binding to water as a result of the larger total surface area provided by the numerous smaller crystallites (Kotek 2007).

With the rediscovery of ionic liquids (ILs) as powerful cellulose solvents by Rogers et al. in 2002, new research efforts were undertaken to develop task specific ILs for the Lyocell process to overcome the shortcomings of NMMO, in particular its thermal instability (Swatloski et al. 2002; Jusner et al. 2021). The ionic liquids of the first generation were imidazolium-based, showed excellent cellulose dissolution (Xu and Wang 2020; Xu et al. 2018) and acceptable spinning properties, but, depending on the chemical composition of the anion, caused a strong degradation of the solute, especially at higher temperatures (Laus et al. 2005; Bentivoglio et al. 2006). In addition, imidazolium ILs were found to react at the C-2 position with the reducing ends of polysaccharides (Ma et al. 2021), thus leading to side reactions (Ebner et al. 2008) such as depolymerization (Dorn et al. 2008; Wendler et al. 2012) or acetylation via transacylation (Abushammala et al. 2017).

In the search for alternative efficient cellulose solvents, researchers from the University of Helsinki and Aalto University suggested superbase-based ILs that enabled the production of cellulose solutions up to a cellulose concentration of $17 \%$ by weight with excellent spinning properties that led to fibers with very high tensile strength and elastic modulus. One of the most suitable superbase-based ILs for dry jet wet spinning to produce fibers with excellent properties has been identified as 1,5-diazabicyclo [4.3.0] non-5enium acetate [DBNH][OAc] (Sixta et al. 2015). The fiber spinning process is denoted as the Ioncell process (Sixta et al. 2015). The Ioncell technology is based on a recyclable ionic liquid, which can dissolve cellulosebased raw materials such as pulp to be spun into manmade cellulosic fibers. The Ioncell process is a closedloop process, which does not produce any waste or releases any harmful chemical to the environment (Elsayed et al. 2020). The resulting Lyocell-type fibers are biodegradable, respire well, feel soft, and-are strong even when wet and do not generate microplastic particles.

During several years of development of the Ioncell process, we were able to develop the textile- 
mechanical properties from initially very brittle and stiff fibers (E-modulus > $30 \mathrm{GPa}$ ) to almost Tencellike fibers (Sixta et al. 2015). The standard Ioncell fibers with conventional birch prehydrolysis kraft pulp with a relatively high xylan content of $6 \%$ exhibit even higher tenacities (49.9 cN/tex vs. $38 \mathrm{cN} /$ tex), but significantly lower extensibility $(12.5 \%$ vs. $15.6 \%)$. Although the toughness modulus of both fibers is already at a very similar level, it will be necessary to further improve the mechanical properties of Ioncell fibers in order to upcycle cellulosic waste textiles to fibers of high durability. Already during the development of the NMMO process (later Tencel), it was discovered that nozzles with a high length-to-diameter ratio of the capillary could achieve a better spinning behavior and that the fibers produced from it had a significantly higher toughness (Zikeli et al. 1992).

The aim of this work was to develop strategies to produce a man-made cellulose fiber with a tensile strength (59 cN/tex) and a modulus of toughness (128 MPa) gradually approaching those of polyester fibers. Similar to the the Super 3 cord spinning process, a softwood prehydrolysis kraft pulp with a very low proportion of low-molecular chains and an increased average molecular weight compared to a conventional rayon pulp was used as raw material in the Ioncell spinning process.

We have not only showed the effect of high purity wood pulp but also showed the effect of using shorter and longer spinneret capillaries into the fiber properties. Using dynamic simulation, we have presented the effect of both pulp and spinneret capillary in the flow behavior of the cellulose solution before it enters into the airgap. In addition, we have investigated how the high toughness of cellulose based fibers can be related to the structural properties of the fiber, the macromolecular and chemical properties of the pulp used and the aspect ratio of the cylindrical part of the spinneret.

\section{Experimental part}

Materials

High-purity pine prehydrolysis Kraft pulp additionally purified with cold caustic extraction (Buckeye-V5) produced by Georgia Pacific (intrinsic viscosity, CUEN, ISO $5351 / 1$, of $594 \mathrm{ml} / \mathrm{g} ; M_{\mathrm{n}}=96.5 \mathrm{~kg} / \mathrm{mol}$ and $\mathrm{M}_{\mathrm{w}}=209 \mathrm{~kg} / \mathrm{mol}$, calculated by GPC-MALLS) was used. The pulp is further denoted as HPG-pulp (High purity pulp). Low-purity birch pre-hydrolysis Kraft pulp (Enocell) denoted as STG-pulp (Standard grade Pulp), $482 \mathrm{ml} / \mathrm{g} ; \mathrm{M}_{\mathrm{n}}=49.3 \mathrm{~kg} / \mathrm{mol}$ and $\mathrm{M}_{\mathrm{w}}=$ $161.7 \mathrm{~kg} / \mathrm{mol}$. 1,5-diazabicyclo [4.3.0] non-5-ene (99\% Fluorochem, UK) and acetic acid (100\% Merck, Germany) were used to prepare 1,5-diazabicyclo [4.3.0] non-5-ene acetate ([DBNH]OAc) for the dissolution of cellulose. Two different spinneret geometries were used in this study which were ordered from Enka Tecnica, Germany. Both spinnerets contain 200 holes having $100 \mu \mathrm{m}$ diameter with capillary length of either $20 \mu \mathrm{m}$ (L/D 0.2) with entrance angle $60^{\circ}$ or $200 \mu \mathrm{m}$ (L/D 2) with entrance angle $10^{\circ}$.

Dissolution of the pulp and filtration

The air-dried pulps were dissolved in melted ([DBNH]OAc) (melted at $80{ }^{\circ} \mathrm{C}$ for $2 \mathrm{~h}$ ) in a vertical kneader system. The mixture of pulp and the IL was kneaded for $1.5 \mathrm{~h}$ at $80{ }^{\circ} \mathrm{C}$ and $30 \mathrm{rpm}$ under reduced pressure (10-50 mbar). After the dissolution, the solutions were filtered using a hydraulic filter press (5 $\mu \mathrm{m}$ fine metal filter mesh, Gebr. Kufferath AG, Germany) at $85{ }^{\circ} \mathrm{C}$ with a pressure of $\sim 2 \mathrm{MPa}$. The purpose of the filtration was to remove undissolved particle which might affect the spinnability. The dopes were then stored in a cold room $\left(4{ }^{\circ} \mathrm{C}\right)$ to solidify.

Rheological properties measurement

The rheological behavior of the dope was measured using Anton Paar MCR 302 rheometer having parallel plate geometry (plate diameter $=25 \mathrm{~mm}$; gap size $=$ $1 \mathrm{~mm}$ ). The dynamic strain sweep tests were performed with a $0.5 \%$ strain in a temperature range of 60-100 ${ }^{\circ} \mathrm{C}$ over an angular velocity range of $100-0.1 \mathrm{~s}^{-1}$. Complex viscosity and the dynamic moduli were recorded. The zero-shear viscosity was calculated using cross viscosity model assuming that the Cox-Merz rule is valid.

Dry-jet wet spinning and fiber washing

Dry-jet wet spinning of fibers was performed using a customized laboratory piston spinning unit (Fourné Polymertechnik, Germany). The solidified dope was melted in the cylinder at $80{ }^{\circ} \mathrm{C}$ to obtain the required 
viscous and air bubble free dope. The molten solution was extruded through spinnerets (200 holes; $100 \mu \mathrm{m}$ diameter, cylindrical length (L)-to-diameter (D), L/D 0.2 and 2). The filaments were coagulated in a water bath $\left(10{ }^{\circ} \mathrm{C}\right)$ keeping an air gap of $0.5 \mathrm{~cm}$ and further guided by Teflon rollers to the godet (velocity varied from 5 to $80 \mathrm{~m} \mathrm{~min}^{-1}$ depending on the obtained draw ratios). The fibers were washed with hot water $\left(80^{\circ} \mathrm{C}\right)$ for $2 \mathrm{~h}$ under continuous magnetic stirring (the water was changed every $30 \mathrm{~min}$ ). Fibers were air-dried after washing.

Molar mass distributions and chemical composition

The molar mass distribution (MMD) of the pulps was measured using a Dionex Ultimate 3000 HPLC system set-up equipped with a Shodex DRI (RI-101) detector, and a Viscotek/Malvern SEC/MALS 20 multi-angle light-scattering (MALS) detector. After solvent exchange (water/acetone/DMAc), the samples were dissolved in a saturated $\mathrm{LiCl} / \mathrm{DMAc}$ solution followed by the dilution to reach an eluent concentration of 0.9 wt\% LiCl/DMAc. $100 \mu$ of each sample solution were placed into the four columns system (PLgel MIXED-A) operating at a flowrate of $0.75 \mathrm{ml} / \mathrm{min}$. A narrow polystyrene standard $\left(\mathrm{M}_{\mathrm{w}}=96000 \mathrm{~g} / \mathrm{mol}\right.$, $\mathrm{Ð}=1.04)$ was used to obtain the detector constants for MALS and DRI, whereas a broad polystyrene sample $\left(\mathrm{M}_{\mathrm{w}}=248000 \mathrm{~g} / \mathrm{mol}, \mathrm{Ð}=1.73\right)$ was applied to test the calibration of the detectors. According to Potthast et al., a $\partial \mathrm{n} / \partial \mathrm{c}$ value of $0.136 \mathrm{ml} / \mathrm{g}$ was reported for cellulose dissolved in $\mathrm{LiCl} / \mathrm{DMAc}$ $(0.9 \%)$.

The carbohydrate and hemicellulose content were determined according to the NREL/TP-510-42,618 (Sluiter et al. 2008) measured by high performance anion exchange chromatography with pulse amperometric detection (HPAEC-PAD) using Dionex ICS3000 system.

Mechanical properties analysis of the fibers

The tensile properties of the fibers were measured using an automatic single-fiber tester Favigraph instrument (Textechno, Germany) with at least 0.06 $\mathrm{cN} /$ tex pretension in the condition state and 0.25 $\mathrm{cN} /$ tex in the wet state. Tenacity and elongation of the fibers were measured both in conditioned and wet state. 20 fibers from each sample were tested at $20 \pm 2{ }^{\circ} \mathrm{C}$ and $65 \pm 2 \% \mathrm{RH}$. The gauge length was $20 \mathrm{~mm}$ and speed $20 \mathrm{~mm} / \mathrm{min}$. The elastic modulus was calculated from the slope of the stress - strain curve of the fiber based on ASTM D2256 standard using MATLAB (MathWorks Inc.).

The total cellulose orientation of the fibers was measured via polarized light microscopy (Zeiss Axio Scope) with a $5 \lambda$ Berek compensator. The birefringence $(\Delta \mathrm{n})$ was calculated using the polarized light retardation value which was divided by fiber thickness calculated from the linear density value (density of cellulose was considered as $1.5 \mathrm{~g} / \mathrm{cm}^{3}$ ). The total orientation was obtained by further dividing $\Delta \mathrm{n}$ by the maximum birefringence value (0.067) determined for cellulose (Adusumalli et al. 2009).

X-ray diffraction analysis

X-ray diffraction data of the precursor fiber were collected in the transmission setting of a SmartLab instrument (RIGAKU) operated at $45 \mathrm{kV}$ and $200 \mathrm{~mA}$. Cellulose fibers were ground using a Wiley mill having $60 \mu \mathrm{m}$ mesh size. The samples were then pressed into disks using a pellet press instrument with constant force for $30 \mathrm{~s}$. Powder diffraction data were collected from $5^{\circ}$ to $60^{\circ} 2 \theta$ by $\theta / 2 \theta$ setting. Scattering profile were corrected for smoothing, subtracting air scattering, and subtracting inelastic contribution. Guizani et al. presented the detailed smoothing procedure which was used to subtract the amorphous cellulose contribution from remained elastic scattering profile (Guizani et al. 2020). Thus, estimated amorphous contribution $\left(I_{b k g}(2 \theta)\right)$ is used to estimate the crystallinity index (CI) using a range from $9^{\circ}$ to $50^{\circ}$ 20:

$C I=100 * \frac{\int I(2 \theta) d 2 \theta-\int I_{b k g}(2 \theta) d 2 \theta}{\int I(2 \theta) d 2 \theta}$

The background corrected profiles were fitted with four pseudo-Voigt functions for (1̄̄0), (110), (020), and (002) peaks for cellulose II (Langan et al., 2001). The (002) peak was added because there was a visible shoulder for the peak in this $\theta / 2 \theta$ experimental geometry. The Scherrer equation was used to estimate the crystal widths $\left(\mathrm{CW}_{\mathrm{hkl}}\right)$ as follows:

$$
C W_{h k l}=\frac{K \lambda}{\beta_{h k l} \cos \theta}
$$


where $\mathrm{K}=0.90$ is the shape factor, $\lambda$ is the $\mathrm{X}$-ray wavelength, $\beta_{\mathrm{hkl}}$ is the full width at half maximum (FWHM) of the diffraction peak in radians and $\theta$ is the diffraction angle of the peak. Due to the significant overlap of (110) and (020) peaks, the crystal widths were reported as average values.

The orientation distribution between fiber axis and the crystallographic (020) lattice plane was estimated using azimuthal scans obtained from the (020) lattice plane of cellulose II allomorph at $21.9^{\circ} 2 \theta$.

$\cos ^{2} \varphi_{020}=\frac{\int_{0}^{\pi / 2} \boldsymbol{I}\left(\varphi_{020}\right) \sin \varphi_{020} \cos ^{2} \varphi_{020} \boldsymbol{d} \varphi}{\int_{0}^{\pi / 2} \boldsymbol{I}\left(\varphi_{020}\right) \sin \varphi_{020} \boldsymbol{d} \varphi}$

The orientation distribution from equatorial diffraction further converted to the orientation distribution between fibre and crystallographic c-axis $\cos ^{2} \varphi_{c}$ assuming cylindrical symmetry:

$\cos ^{2} \varphi_{c}=1-2 \cos ^{2} \varphi_{020}$

Hermans orientation parameter $\left(\boldsymbol{f}_{\boldsymbol{W A X D}}\right)$ was estimated by:

$f_{\text {WAXD }}=\frac{3 \cos ^{2} \varphi_{c}-1}{2}$

Small angle neutron scattering (SANS) analysis

The cellulose fibres were filled in a quartz tube and vacuum dried for $3 \mathrm{~h}$ at $30{ }^{\circ} \mathrm{C}$. Then, samples were deuterated by the continuous flow of moisturized argon gas bubbling through $\mathrm{D}_{2} \mathrm{O}$ solvent overnight. The deuterated fibres were then dried under the air flow of dry argon gas for $3 \mathrm{~h}$. Quartz tubes were sealed using a wax.

The prepared samples in quartz tube were set vertically in a sample holder. SANS data were collected at the D22 instrument at the Institut Laue Langevin, France. The configurations used to reach a scattering vector Q-range of ca. $0.01-0.1 \AA^{-1}$ were $5 \mathrm{~m}$ sample-to-detector distance, $5.6 \mathrm{~m}$ collimation length and a neutron wavelength of $6 \AA$ with $10 \%$ of the wavelength band. For the background estimation, data were collected at $1.5 \mathrm{~m}$ sample-to-detector distance. The neutron beam size was collimated to be $1 \mathrm{~cm} \times 0.1 \mathrm{~cm}$ at the sample position. Exposure times were 5-10 min. The scattering intensity was reduced using GRASP software where the data were corrected for exposure time, incident neutron flax per unit exposure area, unit solid angle for each pixel. Finally, the data were placed in the absolute scale using the direct beam measurement method. Microscopic scattering cross section in units of $\mathrm{cm}^{2}$ at the edge of $1.5 \mathrm{~m}$ detector $\left(\frac{d \sigma}{d \Omega}\right.$ edge $)$ which corresponds to a scattering vector $\mathrm{Q}=0.4 \AA^{-1}$ was used to obtain the incoherent cross section of samples. Assuming the incoherent scattering of cellulose polymer was dominant, the thicknesses of the samples $\left(\boldsymbol{T}_{\text {fibre }}\right)$ were estimated from the scattering data as follows:

$\boldsymbol{W}_{\text {fibre }}=\boldsymbol{M}_{\text {cell }} \frac{\frac{d \sigma}{d \Omega_{\text {edge }}} \times 10^{24}}{I C X_{\text {glu }}} \frac{1}{N_{A}}$

$T_{\text {fibre }}=\frac{W_{\text {fibre }}}{\rho_{\text {fibre }} A}$

where $\boldsymbol{W}_{\text {fibre }}$ is a weight of the sample, $\boldsymbol{M}_{\text {cell }}=162.1$ is a molecular weight of a monomer of cellulose $\left(\mathrm{C}_{6} \mathrm{H}_{10} \mathrm{O}_{5}\right), \boldsymbol{I} \boldsymbol{C} \boldsymbol{X}_{\text {glu }}=868.8$ (barn) is an incoherent scattering cross section per a glucose unit, $N_{A}=$ $6.02 \times 10^{23}$ is the Avogadro constant, $\rho_{\text {fibre }}=1.5(\mathrm{~g} /$ $\left.\mathrm{cm}^{3}\right)$ is a density of the bulk cellulose fibre and $\boldsymbol{A}=0.1$ $\left(\mathrm{cm}^{2}\right)$ is a neutron exposure area. The calculated sample thicknesses from the incoherent backgrounds were used to convert a microscopic cross section into a macroscopic cross section in units of $\mathrm{cm}^{-1}$.

The 1D longitudinal slices were exported from the GRASP software for each pixel lines of the detector. The scattering vector perpendicular to fibre axis $\left(Q_{x}\right)$ of obtained 1D profile contains small fluctuation (maximum ca. $0.0004 \AA^{-1}$ at the edge of detector) based on the pixel position of the detector, but this fluctuation did not have a significant effect on the analysis in this study. The 1D profiles were fitted with three pseudo-Voigt function for the symmetrical Bragg peaks and for the central scattering. Due to the symmetrical feature of Bragg peaks, parameters of width, amplitude and ratio of Gaussian and Lorentzian of two Pseudo-Voigt function were restrained to be a same value. The fitted intensities of Bragg peak of each 1D slice were then fitted with two Pseudo-Voigt functions. Horizontal scattering vector $\left(Q_{x}\right)$ were used for the horizontal axis of this fitting. The obtained intensity maxima $\left(\mathrm{Q}_{\mathrm{xmax}}, \mathrm{Q}_{\mathrm{ymax}}\right)$ were used to estimate the angle between vertical axis and the scattering vector $(\phi)$, and the repeating distance of tilted crystallites $(\boldsymbol{L})$ : 


$$
\begin{aligned}
& \phi=\frac{180}{\pi} \tan ^{-1} \frac{\left|Q_{x \max }\right|}{\left|Q_{y \max }\right|} \\
& \boldsymbol{L}=\frac{2 \pi}{\boldsymbol{Q}_{y \max }}
\end{aligned}
$$

Scanning electron microscopy

Scanning electron microscope images were taken using Zeiss Sigma VP connected to a secondary electron detector with an acceleration voltage of $1.2-1.5 \mathrm{keV}$. The samples were sputtered with $\mathrm{Au} / \mathrm{Pt}$ for $90 \mathrm{~s}$ at $20 \mathrm{~mA}$.

\section{Fiber fibrillation test}

The fibrillation test was done according to the protocol described previously (Ma et al. 2020). The creation of the micro fibrils of the regenerated STG and HPGbased Ioncell fibers were carried out using a Tefal blender. $1 \mathrm{~g}$ of air-dried regenerated fibre cut into $5 \mathrm{~mm}$ short fibers and diluted with $500 \mathrm{ml}$ of tap water in the blender. The fibre suspension was then mixed for 5 and 10 min under ambient conditions with the rotation speed of the blade of $60 \mathrm{~Hz}$ (approximately $3600 \mathrm{rpm}$ ). Subsequent to the mixing, the suspension was filtered, and the fiber was dried at 60 ${ }^{\circ} \mathrm{C}$ for $2 \mathrm{~h}$.

The dried fiber was then cut into even shorter length $(<1 \mathrm{~mm})$ and diluted with water at a concentration of $1 \mathrm{~g} / \mathrm{l}$. The suspension was mixed well with $2 \%$ gelatin solution (as a fixation media) with a ratio of 1:1. 2 drops of the fiber suspension was dropped onto the objective glass from a certain height in order to keep the fibrils open. A cover slide was placed on top and then the fibrillation of the fibres was examined using an optical microscope. The fibrillation index was calculated as follow:

$I_{f}=\frac{\sum_{L} l}{L}$

where $I_{f}$ being the fibrillation index, 1 is the lengths of the fibrils over the length of the fiber L.

\section{Results and discussion}

The tensile strength of the MMCFs depends on the raw material properties, such as the weight fraction of short-chain molecules, the non-cellulosic components, the average molar mass, molar mass distribution and the spinning parameters (i.e. extrusion velocity, draw ratio, air gap conditioning, spinneret geometry) (Michud et al. 2016). The reference raw material for our Ioncell spinning process is a STG pulp with an intrinsic viscosity of $482 \mathrm{~mL} / \mathrm{g}$, a total hemicellulose content of $7.9 \%$ and an R18 content of $95 \%$. The hemicellulose content is also visible in the molar mass distribution by the weight fraction of short chains, characterized by a degree of polymerization (DP) $<$ 100 (Table 1; Fig. S1). Previously, it was shown that the presence of non-cellulosic compounds alters the perfection of the crystalline structure of the regenerated cellulose fiber and thus reduces the fiber strength (Sixta et al. 2015). In addition, high molecular weight cellulose chains, in combination with a low proportion of the short chain fraction (DP $<100$ ), was hypothesized to contribute to high strength in cellulosic fibers. With relatively equally long cellulose chains, the individual molecules pass through a higher proportion of crystalline and amorphous structural regions. With the high orientation of the molecules along the fiber axis, the extent of hydrogen bonding between the cellulose molecules increases simultaneously, which leads to the formation of a more uniform structure, and thus to a higher resistance to mechanical stress (Michud et al. 2016).

In order to prove these findings, which were obtained mainly in viscose fiber processes (Goetze 1964), a high-purity grade wood pulp, referred to as HPG pulp, was selected for the Ioncell spinning trials. This pulp was produced from pine wood using the prehydrolysis Kraft (PHK) process followed by alkaline extraction at low temperatures (cold caustic extraction or CCE). As a result, both short-chain hemicelluloses and cellulose were largely removed. These properties were validated by the low amount of short chains (DP $<100$ ), hemicelluloses and high R18 contents (Table 1). In contrast to STG-pulp, significant reduction of the short chains with the concomitant increase of the long chains (Table 1; Fig.S1) further justifies the observed properties of HPG-pulp.

The macromolecular properties of the solute, the polymer concentration in the solution, together with 
Table 1 Chemical composition and macromolecular properties of the pulps

\begin{tabular}{|c|c|c|c|c|c|c|c|c|c|c|c|c|}
\hline \multicolumn{8}{|c|}{ Standard specification of pulps } & \multicolumn{5}{|c|}{ Molar mass distribution } \\
\hline Pulp & Wood & Process & $\begin{array}{l}\text { Viscosity } \\
(\mathrm{mL} / \mathrm{g})\end{array}$ & $\mathrm{DP}_{\mathrm{V}}$ & $\begin{array}{l}\mathrm{R} 18 \\
(\%)\end{array}$ & $\begin{array}{l}\text { Hemi- } \\
\text {-cellulose } \\
(\%)\end{array}$ & $\begin{array}{l}\text { Brightness } \\
\text { (\% ISO) }\end{array}$ & $\begin{array}{l}\mathrm{Mw} \\
(\mathrm{GPC}) \\
\mathrm{Kg} / \mathrm{mol}\end{array}$ & $\begin{array}{l}\mathrm{Mn} \\
(\mathrm{GPC}) \\
\mathrm{Kg} / \mathrm{mol}\end{array}$ & $\begin{array}{l}\text { PDI } \\
\mathrm{Mw} / \\
\mathrm{Mn}\end{array}$ & $\mathrm{DP}<100$ & $\mathrm{DP}>2000$ \\
\hline STG & Birch & PHK & 482 & 1150 & 95.0 & 6.8 & 1.1 & 161.7 & 49.3 & 3.3 & 7.1 & 11.3 \\
\hline HPG & Pine & $\begin{array}{l}\text { PHK- } \\
\text { CCE }\end{array}$ & 594 & 1510 & 98.2 & 0.7 & 0.6 & 209.8 & 96.6 & 2.2 & 1.1 & 19.2 \\
\hline
\end{tabular}

the solvent properties were previously demonstrated to determine the rheological behavior and spinnability of the dope (spinning solution) (Michud et al. 2016; Asaadi et al. 2018b). The rheological properties were determined using oscillatory shear measurements, and complex viscosity and the dynamic moduli were obtained as a function of the angular frequency (Fig. 1; Table S1). Previous studies defined the optimum spinning criteria of cellulose solution in [DBNH][OAc] having zero-shear viscosity of 25.000-30.000 Pa.s and a cross-over point (COP) of the dynamic moduli of 3000-5000 Pa with a crossover frequency of $1 \mathrm{~s}^{-1}$ (Michud et al. 2016; Asaadi et al. 2016; Ma et al. 2018). The reference cellulose solution with 13 wt $\%$ STG pulp has rheological values within the optimum spinning window comprising a zeroshear viscosity of 25,000 and a COP of $3500 \mathrm{~Pa}$ at an angular frequency of $1 \mathrm{~s}^{-1}$ at the spinning temperature of $79-80{ }^{\circ} \mathrm{C}$ (Fig. 1).

However, in case of $13 \mathrm{wt} \%$ HPG pulp solution, the zero shear viscosity increased (49,600 Pa.s) along with an increase in dynamic moduli (4570 Pa)
(Table S1). The high molecular weight of HPG pulp increases the average chain length per molecule providing more entanglements per volume. Previous findings demonstrated that more entanglements per volume restricted the movement of the individual cellulose chain, resulting in increased zero shear viscosity (Graessley 1980). Along with the increase of viscosity, shear thinning behavior increases resulting in the increase of complex moduli at a lower frequency (Chen et al. 2009). Compared to $13 \mathrm{wt} \%$ STG pulp, the COP shifted to a lower frequency $\left(0.52 \mathrm{~s}^{-1}\right)$ in $13 \mathrm{wt} \%$ HPG solution (Fig. 1; Table S1).

It is known that a narrower molar mass distribution, expressed in a lower polydispersity index (PDI), is associated with higher dynamic moduli at COP (Ma et al. 2018; Sixta et al. 2015). Thus, in contrast to STG (PDI 3.3), a narrower molecular weight distribution of HPG (PDI 2.2) may explain the increase in the complex moduli at COP (Table S1; Fig. 1).

Michud et al. demonstrated that an increased solute concentration reduced the molecular mobility of the cellulose chains due to an increase in intermolecular
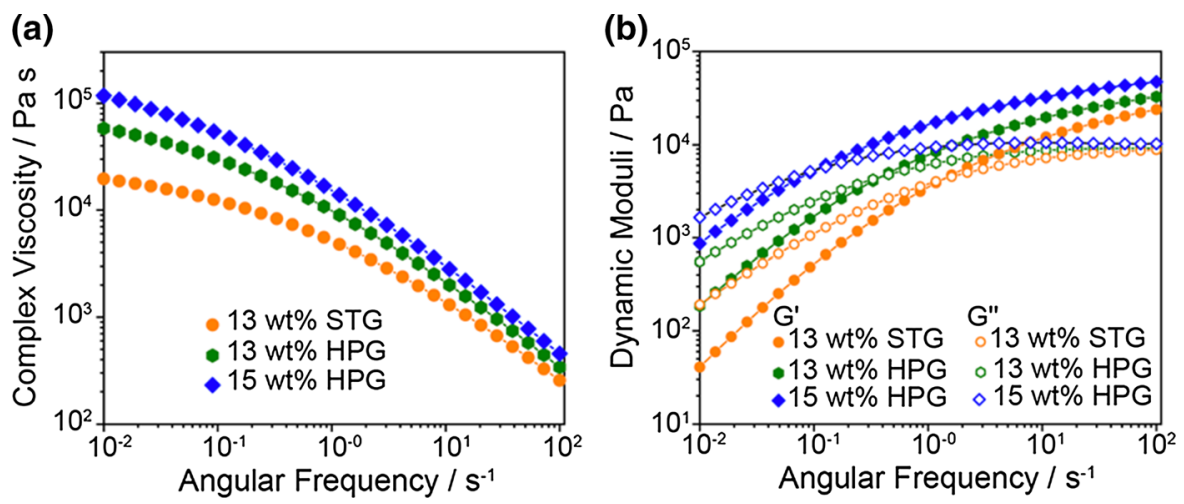

Fig. 1 Rheological properties of the pulp solutions a The change in complex viscosity $\eta 0^{*}$, dynamic moduli ( $\left.G^{\prime}=G^{\prime}\right)$ and angular frequency $\omega$ with different solute concentrations and temperatures 
action and created stronger chain entanglement. This robust chain entanglement created a strong polymer network, which led to a higher dynamic modulus at COP (Michud et al. 2016). In line with this previous study, a higher concentration of HPG (13 to $15 \mathrm{wt} \%$ ) led to a further increase in both the zero-shear viscosity and dynamic modulus at COP (Fig. 1).

Good spinnability is characterized-among other criteria-by the possibility to stretch the fluid filament in an air gap and to align the cellulose molecules along the chain axis while reducing the linear density. The extent of the filament stretch is characterized as the ratio of the take-up velocity to the extrusion velocity, known as the draw ratio (DR). Following previous studies, spinnability of the dope can be defined as follows: DR $<2$ non-spinnable, $2-8$ poor, $8-14$ good and $>14$ excellent (Haslinger et al. 2019; Asaadi et al. 2016). In this study, the complex viscosity profiles including the dynamic moduli for both $13 \mathrm{wt} \%$ and 15 wt $\%$ of HPG were above the optimum range, yet the spinnability was high. A DR of at least 14 to 18 was achieved in all the spinning trials, demonstrating excellent spinnability. The target DR of the fibers is 8 to 12 , where the fibers have linear density or titer of 1-2 dtex, suitable for textile applications.

During dry-jet wet spinning, the viscoelastic polymer solution is extruded through the spinneret containing a convergent conical nozzle with a cylindrical capillary of a certain length (Fig. 2). The cellulose polymer molecules having a random-coil formation in solution are pre-orientated by shear forces and

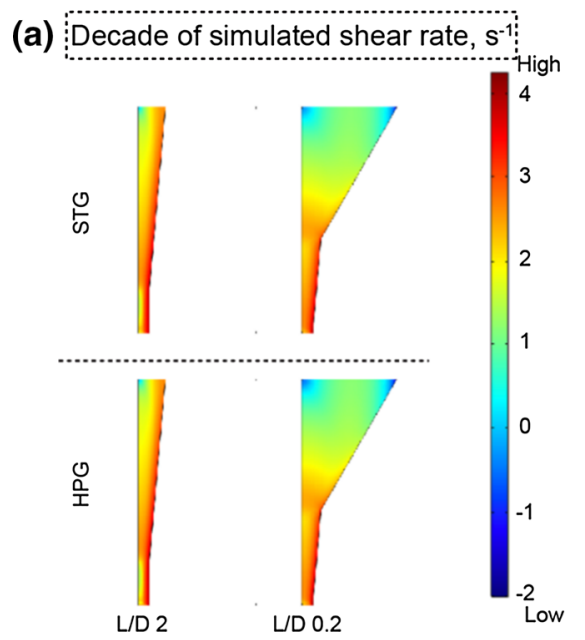

acceleration as they flow through the spinneret capillary. The sudden release of the shear stress when exiting the spinneret and entering the air gap causes the polymer chains to relax, resulting in a lateral expansion of the filament, known as die swell. This die swell, however, is often overcompensated when the filaments are stretched. The viscoelasticity of the cellulose solution counteracts the elongational force and strain hardening takes place along the vertical filament axis in the air gap (Sixta et al. 2015). The extruded filaments experience a rapid cooling because of the sudden change in temperature when exiting the spinneret and because of the elongation which leads to a rapid entropy change of the solution.

The combination of shear and extensional stress induce polymer orientation parallel to the filament axis which is preserved upon rapid coagulation in the spin bath. Although most of the improved orientation is due to the stretching of the filaments in the air gap, it is obvious that the flow conditions in the capillaries of the spinneret also contribute to the alignment of the cellulose molecules. There are two characteristics of the flow in the spinneret that would enhance the emerging crystallinity. First, as the capillary narrows in the flow direction the flow is accelerated, causing a strain-induced deformation. Second, the shear flow reduces the entanglement of the polymer chains, while at the same time their orientation in the flow direction increases. However, the shear flow can also disrupt and impede the formation of lateral hydrogen bonds.

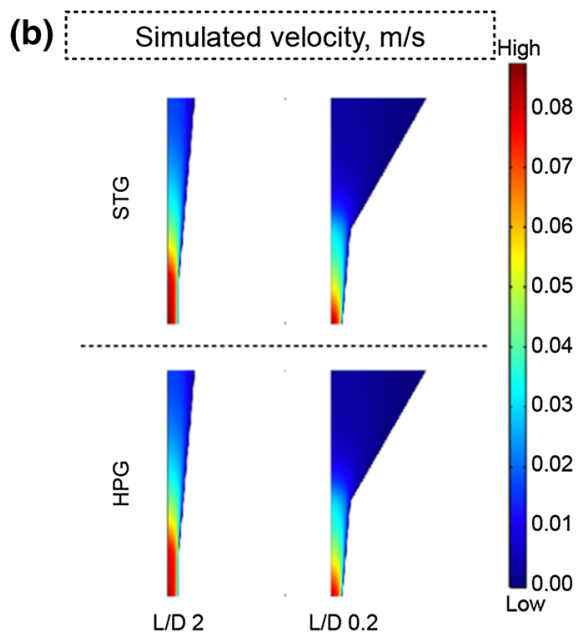

Fig. 2 Fluid dynamic simulation based on a COMSOL model- a decade of simulated shear rate s ${ }^{-1}$ (left capillary L/D2 and right capillary L/D 0.2), b simulated velocity $\mathrm{m} / \mathrm{s}$ (left capillary L/D2 and right capillary L/D 0.2) 
The molecular alignment of the cellulose strands was evaluated by simulating the axial symmetric laminar flow of the cellulose solution with the COMSOL Multiphysics software. At first, the crossmodel parameters were estimated using shear rateviscosity data of the dope by fitting the model to the data in Wolfram Mathematica (Fig. S2). Afterwards, the simulation of velocity and shear rate distributions in the spinneret was done by COMSOL Multiphysics using Mathematica estimates.

This study encompasses two different geometries of the capillaries of the spinneret, both having same hole diameter of $100 \mu \mathrm{m}$, but different capillary lengths of $20 \mu \mathrm{m}$ (L/D 0.2) and $200 \mu \mathrm{m}$ (L/D 2). Figure $\mathrm{S} 3$ shows the differences in the profiles of the two capillaries.

Since the shear rate (Fig. 2a) and the velocity (Fig. 2b) in the capillary span several orders of magnitude, the color scale is logarithmic. The simulation revealed differences between the two different geometry cases, but not so much between the two dopes, which were derived from the different pulps. While the shear rate tends to reduce the entanglement of the cellulose molecules and align them with the streamlines, the acceleration of the flow stretches the viscous cellulose solution. Both shear rate and velocity align the cellulose molecules in parallel near the outlet. In a numerical estimation of the effects of the shear flow, the integration of the product of shear force and shear rate via the capillary gives the power transmitted to the dope (Table S2). It is remarkable that there is a clear difference between the two capillaries as well as between the two dopes. The HPG pulp seems to receive more shearing power than the STG pulp (Table S2). In addition, longer capillary resulted in higher viscous power (Table S2). Having higher portion of longer molecular chain compared to STG pulp increased the viscosity of the solution which contributed to higher shearing power. Similarly, the solution experienced higher viscous power upon increased strain in the longer capillary $(\mathrm{L} / \mathrm{D}=2.0$ ). Furthermore, the simulation shows a spatially more dispersed shear rate distribution for $\mathrm{L} / \mathrm{D}=2.0 \mathrm{com}$ pared to $\mathrm{L} / \mathrm{D}=0.2$ (Fig. 2).

It can be assumed that a high shear rate at the beginning of the capillary, when the molecules are still entangled, is more advantageous for disrupting interactions between the cellulose strands. There is constant radial redistribution of the cellulose molecules in the preceding truncated cone with higher shear rate at the entrance of the cylindrical part. At the same time, a high shear rate near the outlet, where the cellulose molecules already form a regular arrangement, can also impede the formation of regular lateral interaction between the molecules belonging to adjacent concentric cylinders. The simulation confirms that longer capillaries $(\mathrm{L} / \mathrm{D}=2.0)$ would better align the fibers along the molecular axis.

The pulp properties showed a considerable influence on the mechanical properties of the fibers. The fiber toughness represents the work needed to fracture the fiber, which can be determined by the area under a stress-strain curve (Zhu et al. 2015). Thus, fiber toughness results from a combination of elongation and tensile strength (Zhu et al. 2015). Fibers spun from the HPG pulp showed better toughness compared to fibers spun from the STG pulp at target draw ratios both in conditioned and wet state (Fig. 3). This data further supports the assumption that the presence of a high share of uniformly longer molecular chains and fewer (non-cellulosic) impurities in the pulp significantly improves the fiber mechanical properties.

The HPG-derived fibers have higher tensile strength or tenacity compared to the STG-based fibers especially at target draw ratios (Table S3). The improvement in tenacity correlates with the higher degree of polymerization (DP) of the HPG pulp. It has been previously reported that a linear relationship between the reciprocal DP and the tenacity of rayon fibers exists over a relatively wide DP range. The slower decrease in tensile strength in the low DP range was explained by changes in crystallinity and size distribution of the morphological units that form the network structure of the fibers (Adusumalli et al. 2009). In addition, according to previous studies, a spinning solution containing higher molecular weight cellulose has a longer relaxation time, thus maintaining a higher molecular orientation, resulting in high tensile strength (Hummel et al. 2016).

Along with the increase of tensile strength, elongation was also improved for HPG-based fibers at target draw ratios (Table S3). Michud et al. showed that the presence of longer cellulose chain molecules in a solution promotes uniform and homogenous interactions between the cellulose chains resulting in a more cohesive cellulose network formation during the regeneration process. This phenomenon improves the elongation properties of fibers 
(a)

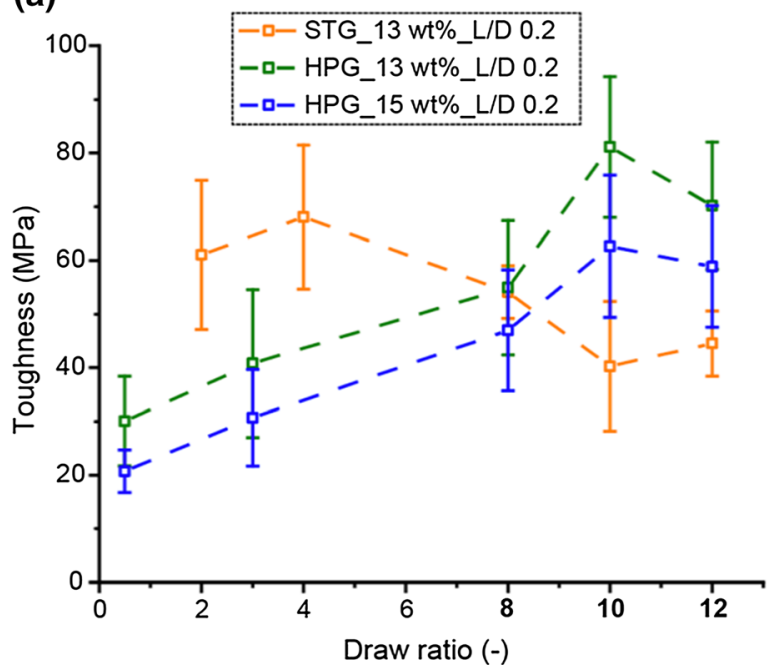

(b)

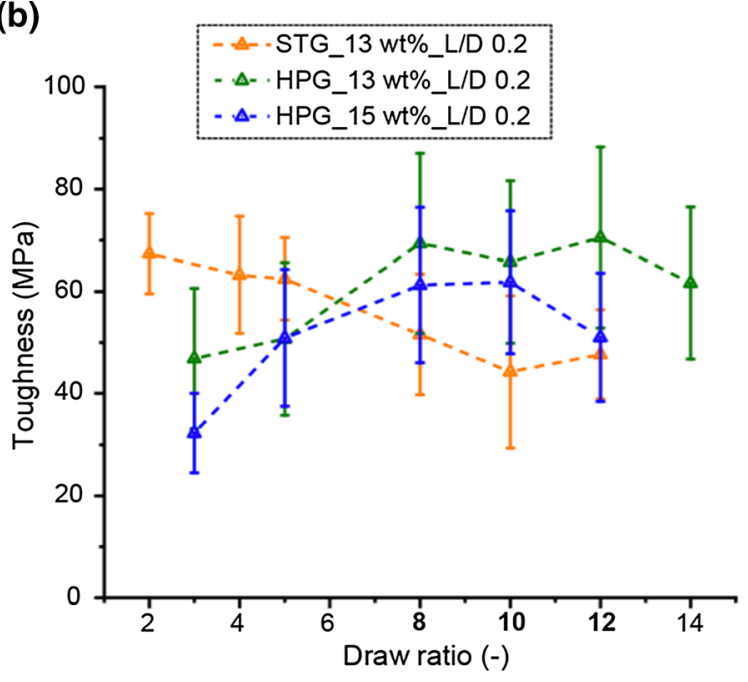

Fig. 3 Influence of the macromolecular pulp properties of two different pulps (STG and HPG) on the toughness of Ioncell fibers produced therefrom as a function of the draw ratio a) conditioned state b) wet state

by promoting stability of the liquid thread in the airgap (Michud et al. 2016). Additionally, with increased draw ratio, the contact area between adjacent fibrils increases as the diameter of the fibril decreases. According to COMSOL simulation, increased shear power of HPG pulp solution contributed to a better pre-orientation of the cellulose molecules before entering the airgap. An improved pre-orientation along with a stable cellulose network could create a more extended $\mathrm{H}$-bonded supramolecular structure in the HPG-based fibers resulting in at a higher toughness at the target draw ratios.

In an earlier publication, it was shown that the mechanical properties of Ioncell fibers increased with an increase in cellulose concentration in the dope up to $17 \mathrm{wt} \%$, which was explained by the strong preorientation of the cellulose chains (Sixta et al. 2015). Hong et al. demonstrated that in highly concentrated solution the enhanced proximity of solute molecules promotes tight packing during the spinning and coagulation process. This led to the formation of a higher degree of order of the cellulose molecules in the resulting fiber (Hong et al. 2013). Hence, the concentration of HPG-pulp in the dope was increased up to 15 $\mathrm{wt} \%$ to observe the change in mechanical properties of the fiber. Unexpectedly, the increase in the concentration of the HPG pulp in the ionic liquid solution did not improve the fiber mechanical properties. The fiber toughness remained constant at DR $>8$ and decreased at DR $>10$ (Fig. 4). With the use of the HPG pulp in this work, the pulp with a viscosity of $594 \mathrm{~mL} / \mathrm{g}$ has a much higher molecular weight, so that, as can be clearly seen in Figure S4, the orientation increases more at lower draw ratios at $15 \mathrm{wt} \%$ than at $13 \mathrm{wt} \%$, as expected, but decreases again as the draw ratio progresses, while at the lower polymer concentration the overall orientation increases even further up to a DR of 10. Obviously, with this combination of high polymer concentration and high molecular weight, the extensional viscosity becomes so high above a certain stretching ratio, which can lead to partial cohesive fractures which in turn reflects a stagnating or even decreasing modulus of toughness with increasing DR.

The length of the cylindrical spinneret capillary showed a considerable influence on the fiber toughness of HPG-based fibers both in the conditioned and wet state (Fig. 4). Based on the COMSOL model, it was found that in the longer capillary the viscoelastic solution is more pre-stretched than in the shorter capillary (Fig. 2). Additionally, the molecular alignment increases with the length of cylindrical capillary (L/D). This leads to a stronger orientation of the cellulose molecules along their axis before entering the air gap, which contributes to improved fiber properties. In fact, a capillary ten times longer (20 to $200 \mu \mathrm{m})$ improved the mechanical properties of the fibers spun from $13 \mathrm{wt} \%$ and $15 \mathrm{wt} \%$ HPG pulp. For the $13 \%$ HPG-based fiber, the tenacity improved from 

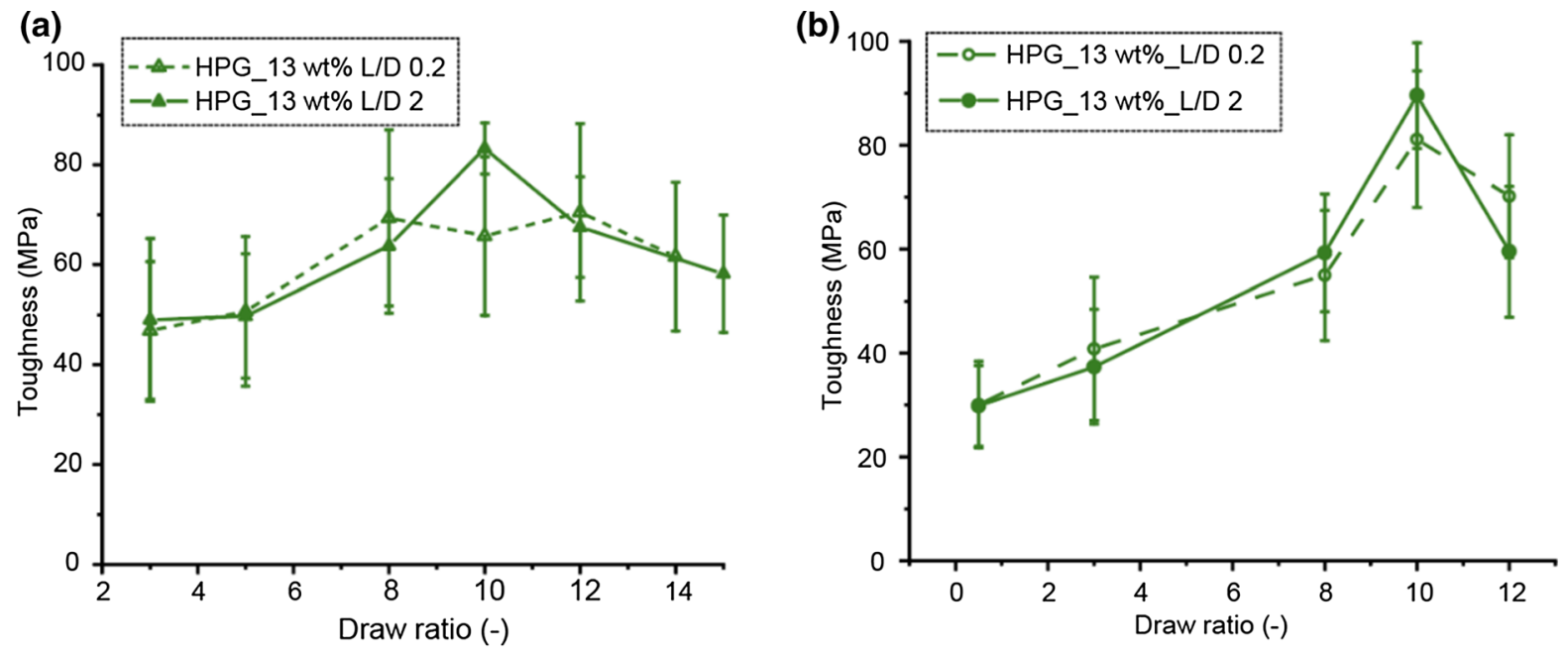

(c)

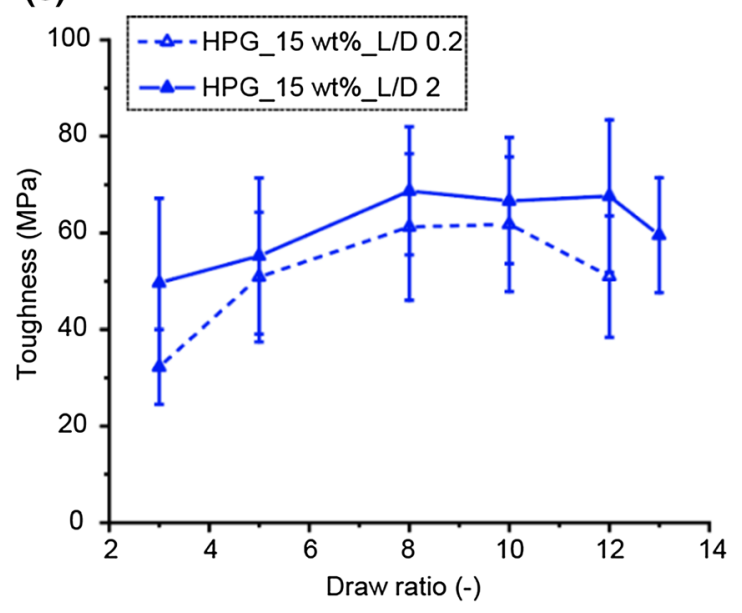

(d)

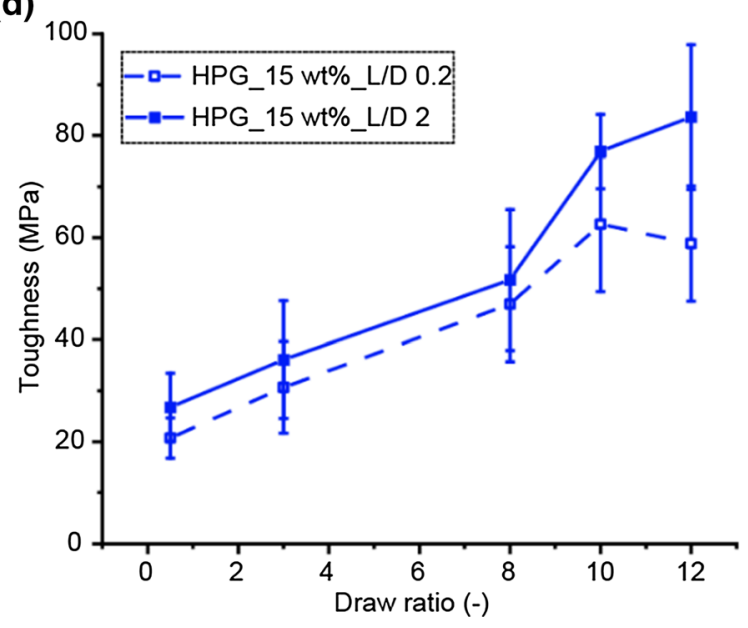

Fig. 4 The effect of the spinneret capillary geometry (L/D 0.2 vs L/D 2) on the mechanical properties of fibers: change in toughness for $13 \mathrm{wt} \%$ HPG in a conditioned state, b wet state; change in toughness for $15 \mathrm{wt} \%$ HPG in conditioned state, $\mathbf{d}$ wet state

$53.2 \mathrm{cN} /$ tex to $61.4 \mathrm{cN} /$ tex at a fiber titer of $1.4 \mathrm{dtex}$ $(\mathrm{DR}=10)$, while elongation increased from 13.7 to $14.7 \%$ (Table S3), resulting in a $27 \%$ increase in the modulus of toughness from 65.8 to $83.3 \mathrm{MPa}$ (Fig. 4 a), the highest toughness value ever published for regenerated cellulose fibers (Fig. S5a \& b). No other commercially available man-made cellulose textile fiber, not even the Super 3 cord fiber (Von Bucher 1968) has a similarly high toughness (Fig. S5a \& b). The longer capillary effect was also obvious in case of 15 wt $\%$ HPG-fibers, where toughness improved with a continuous trend as a function of the draw ratio (Fig. 4).

For both HPG and STG-based fibers, the values of the wet-to-dry tenacity ratio ranged from 0.9 to 1.0 at target DRs. However, for the HPG-based fibers with higher DRs (10 and 12), the wet-to-dry ratio was close to 1 or higher than 1 (Table S4). The wet-to-dry ratio indicates the accessible H-bond network in the loworiented amorphous region or the bonding limitations between ordered crystallites (Asaadi et al. 2018a). During the wet test, the fiber absorbs water in particular in the less-ordered domains resulting in swelling and reduction in tensile strength (Asaadi et al. 2018a). The unchanged wet-tensile properties of HPG-based fibers indicate strong $\mathrm{H}$-bonds even in the highly oriented amorphous zone between the crystallites.

To understand the improved toughness properties, the internal structures of the fibers were studied. The 
mechanical properties of the Lyocell-type fibers prepared with different draw ratios depend on the degree of orientation (both crystalline and amorphous orientation) (Adusumalli et al. 2009). When filaments are stretched to a higher draw ratio, the fibrils orientate more strongly along the axis, thus increasing the orientation. Generally, the tensile strength increases with the increase in orientation, while elongation decreases (Adusumalli et al. 2009; Hummel et al. 2016). However, in this study, the HPG-based fibers showed improved tensile strength with a simultaneous increase in elongation, resulting in higher toughness. With unchanged molecular weight and crystallinity, Krässig and Kitchen repeatedly found a dependence of the tensile strength in the conditioned state on the square of the total orientation of the cellulose molecules for different rayon fibers (Krässig and Kitchen 1961). This correlation was confirmed for Lyocell fibers (Röder et al. 2009). Previous studies showed that the incremental change in orientation properties is obvious until DR 5 and then starts to level off (Sixta et al. 2015; Asaadi et al. 2018b).

Additionally, the fibers show strain-induced crystallization already at lower DR. The change in crystallization at higher draw ratio is not substantial. It has been reported previously that the change in crystallinity of the fibers between DRs of 2-14 was insignificant (Asaadi et al. 2018b). In line with the previous studies, the crystalline orientation parameter derived from X-ray diffraction analyses reached a plateau at a draw ratio of 3 , and no further increase was observed for both HPG- and STG-based fibers (Fig. 5). The crystal size and crystallinity parameters did not increase either (Fig. 5).

As expected, the total orientation measured via the birefringence reaches a plateau at DR $>4$ for HPGbased fibers, where it remains at a constant level up to high DR values (Fig. S4a). Consequently, we did not find the reason for high toughness beyond DR 3 in the crystalline structures of cellulose. Although the changes in orientation, crystal size and crystallinity between different DRs were insignificant, these parameters varied considerably between HPG- and STG-based fibers. HPG-based fibers had higher orientation at low DR but remained similar at high DR. Moreover, HPG-based fibers showed higher crystal size and lower crystallinity as compared to STG-based fibers (Fig. 5).

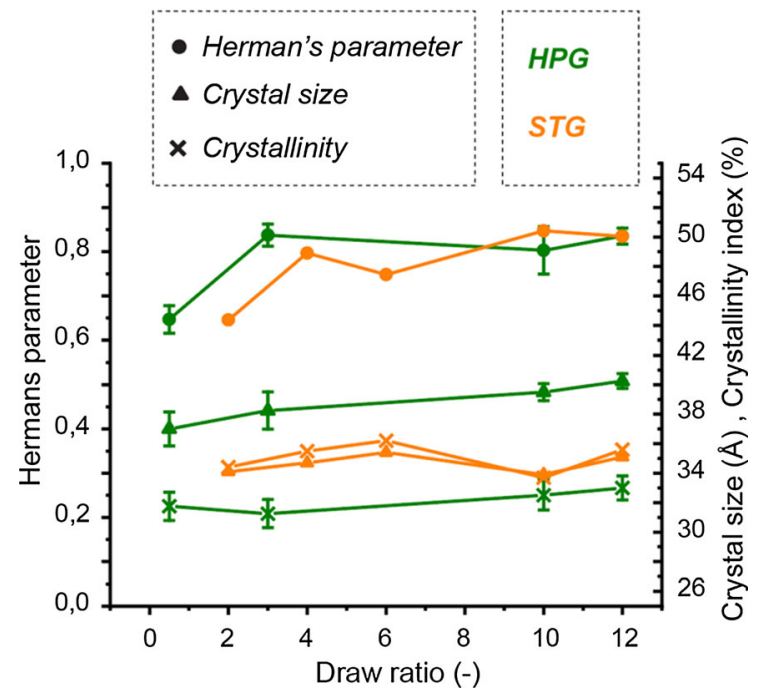

Fig. 5 The change in orientation parameters derived from wide angle X-ray diffraction (WAXD) analyses, crystal size and crystallinity with DR for both HPG and STG-based fibers. The error bar of HPG-based fibers shows the difference due to changing spinneret geometry and concentration

Small angle neutron scattering analysis was employed to study the elementary fibrils structure at nanoscale. The observed 'Bragg peak' in the meridian region of small angle scattering pattern can be attributed to the periodic structures, the long period $\left(\mathrm{L}_{\phi}\right)$, present in the cellulose elementary fibrils. From the intensity distribution of the Bragg peak, the dimensions and shapes of the periodic structure were estimated (Table 2).

By increasing the draw ratio from 1 to 12 for HPGbased fiber samples, the peak maxima of the Bragg peak shifted to the vertex side of elliptical trace. As a

Table 2 The structural parameters of HPG-based fiber samples

\begin{tabular}{lllllll}
\hline Conc & $\mathrm{L} / \mathrm{D}$ & $\mathrm{DR}$ & $\mathrm{L}_{\phi}(\AA)$ & \pm & $\phi\left(^{\circ}\right)$ & \pm \\
\hline 13 & 0.2 & 0.5 & 230 & 4 & 56 & 1 \\
15 & 0.2 & 0.5 & 245 & 9 & 61 & 1 \\
15 & 2 & 0.5 & 234 & 5 & 56 & 1 \\
13 & 0.2 & 1 & 242 & 16 & 59 & 2 \\
13 & 2 & 1 & 246 & 11 & 60 & 1 \\
15 & 2 & 1 & 245 & 17 & 59 & 2 \\
13 & 0.2 & 12 & 364 & 40 & 75 & 2 \\
15 & 2 & 12 & 341 & 36 & 72 & 2 \\
\hline
\end{tabular}


result, the angle between the fiber axis and the scattering vector to the peak, $\phi$, was significantly increased (Fig. 6).

Such a significant increase in $\phi$ due to the change of the DR was not observed in the STG-based fibers (Sawada et al. 2021). The tilt angle, $\phi$, determines the internal strain between the interfibrillar structure of the fiber. An increase in the tilt angle indicates a higher level of interlinks between crystalline and amorphous region in the elementary fibril (Murthy and Grubb 2006). The higher degree of polymerization and the presence of uniformly longer cellulose chains in HPGbased fibers are probably the reason for the higher degree of interlinks between crystalline and amorphous regions. The stretching of the cellulose solution in the airgap causes a gradual formation of $\mathrm{H}$-bond thus promoting the creation of interlinkages within the elementary fibril. Hence, a noticeable increase in the tilt angle $\phi$ of HPG-based fibers at higher DR. Because of these increased interlinkages, the extensional force during the spinning process probably induces the slip of crystallites along with the crystalline alignment, which results in the greater value of $\phi$. It can thus be argued that due to the higher level of interlinkages between crystalline and amorphous region, both tensile strength and elongation increased simultaneously, resulting in increased toughness. In addition to $\phi$, the periodicity or long period $\mathrm{L}_{\phi}$ of the lamellar plane also increased considerably at higher draw ratio. Previous study showed that $\mathrm{L}_{\phi}$ tends to increase with a higher amorphous orientation of the fiber (Murthy et al. 1998, 2000; Schurz and Lenz 1994a).

The microvoids orientation in Lyocell fibers is significantly higher as compared to man-made cellulose fibers with a higher extensibility such as viscose fibers (Schurz and Lenz 1994a). This was confirmed for Ioncell fibers made of STG pulp, while unexpectedly the microvoids orientation of HPG-based Ioncell fibers is considerably lower over the entire DR range compared to the STG-based Ioncell fibers (Fig. S6). This is a further indication of a superior toughness of Ioncell fibers produced from an HPG pulp. This observation confirms that not only the classical structural features such as crystallite dimensions, size and orientation of the crystalline and amorphous regions determine the fiber performance, but also their internal voids, their shape and orientation (Schurz et al. 1995).
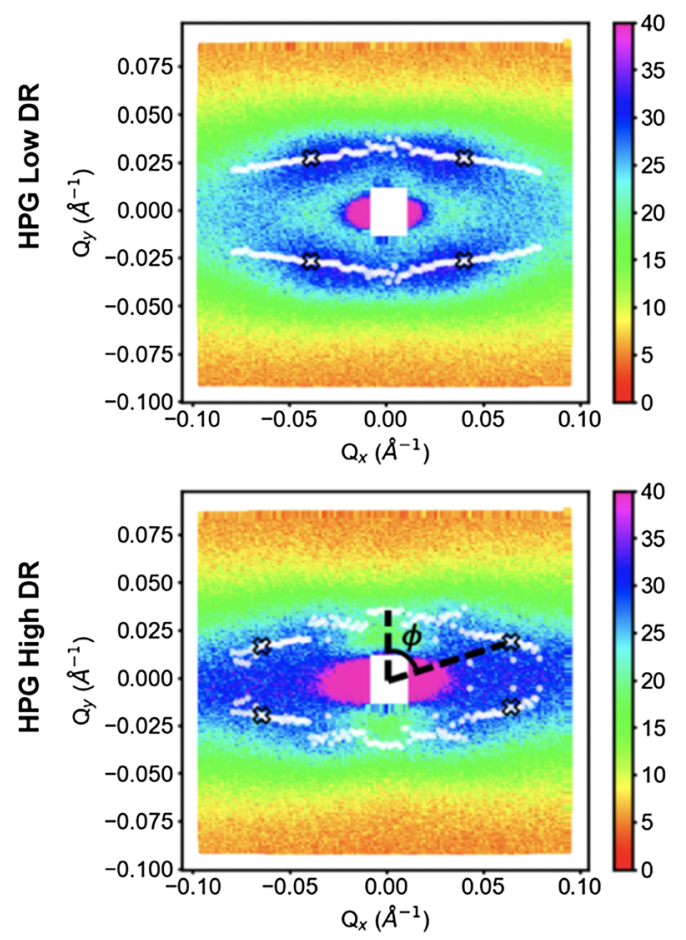

Structural parameters

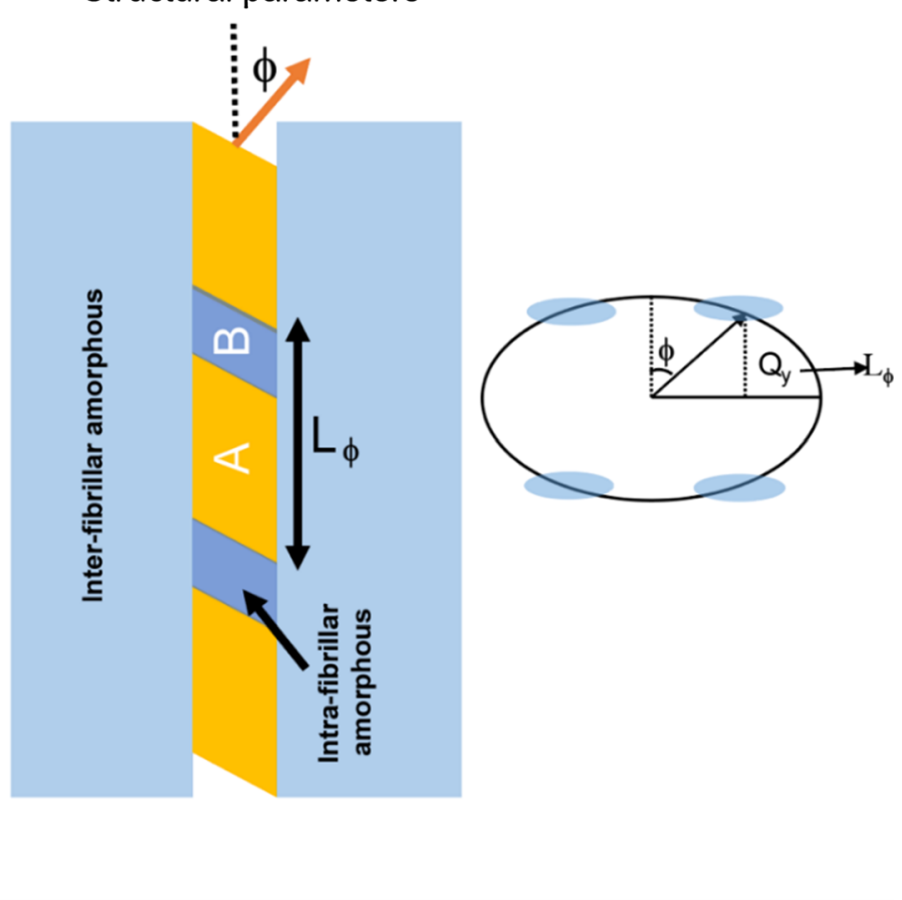

Fig. 6 The small angle scattering pattern of HPG-based fiber samples of low and high draw ratio (left); the structural parameters on the right where $\mathrm{Q}$ is the scattering vector, $\mathrm{A}$ is the crystalline region, $\mathrm{B}$ is the amorphous region; $\phi$ is tilt angle and $\mathrm{L}_{\phi}$ is the periodicity 
Fiber morphology and fibrillation

The fiber morphology varies with the cellulose content, orientation and the presence of impurities (Asaadi et al. 2018a). The cross section of the high tenacity, high toughness HPG-based Ioncell fiber (HPG-13 wt\% DR10) was compared with commercial cellulose fibers (Fig. 7). The observed morphology of Ioncell fiber (DR10) is similar to the NMMO-based Lyocell fiber, which has a circular cross-section with highly oriented nanofibrils across the fiber body (Fink et al. 2001; Michud et al. 2016). The viscose and Lenzing ${ }^{\mathrm{TM}}$ modal fibers show a kidney-shaped crosssection with pronounced grooves along the fiber (Zhang et al. 2018). Lyocell fibers have uniform structures. In contrast to Lyocell fibers, viscose and Lenzing $^{\mathrm{TM}}$ modal fibers have a lower crystallinity index and a less homogenous structure containing more cavities along with considerably lower mechanical properties (Zhang et al. 2018). Interestingly, the Super 3 cord fiber has a slightly kidney-shaped crosssection, a very dense and uniform fibrillar structure and a few visible longitudinal grooves. The fibrillar structure of the high toughness-Ioncell fiber (83 MPa) was quite similar to that of the Super 3 cord fiber (74 MPa), although the shape was different (Fig. 7).

Fibrillation is a common phenomenon of manmade cellulosic fibers. The microfibrils on the fibers surface are formed by wet abrasion due to the breakage of the lateral cohesion of the crystals (Mortimer and Peguy 1996; Udomkichdecha et al. 2002; Zhang et al. 2006). The effect is more pronounced when fibers are swollen, for instance under alkaline conditions and simultaneous application of abrasive forces (Goswami et al. 2009; Zhang et al. 2005). It is known that fibers with high amorphous and crystalline orientation (Lyocell or polynosic) have a very strong tendency to fibrillate upon wet abrasion (Sharma et al. 2021), whereas regenerated cellulose fibers with low orientation, such as regular viscose fibers, but also Lenzing $^{\mathrm{TM}}$ modal fibers, have practically no tendency to fibrillate (Mortimer and Peguy 1996) (Fig. S7). The high fibrillation tendency of Lyocell fibers was explained by the few lateral crosslinks between different elementary fibrils caused by their rather isolated and intact cellulose crystallites. In contrast,
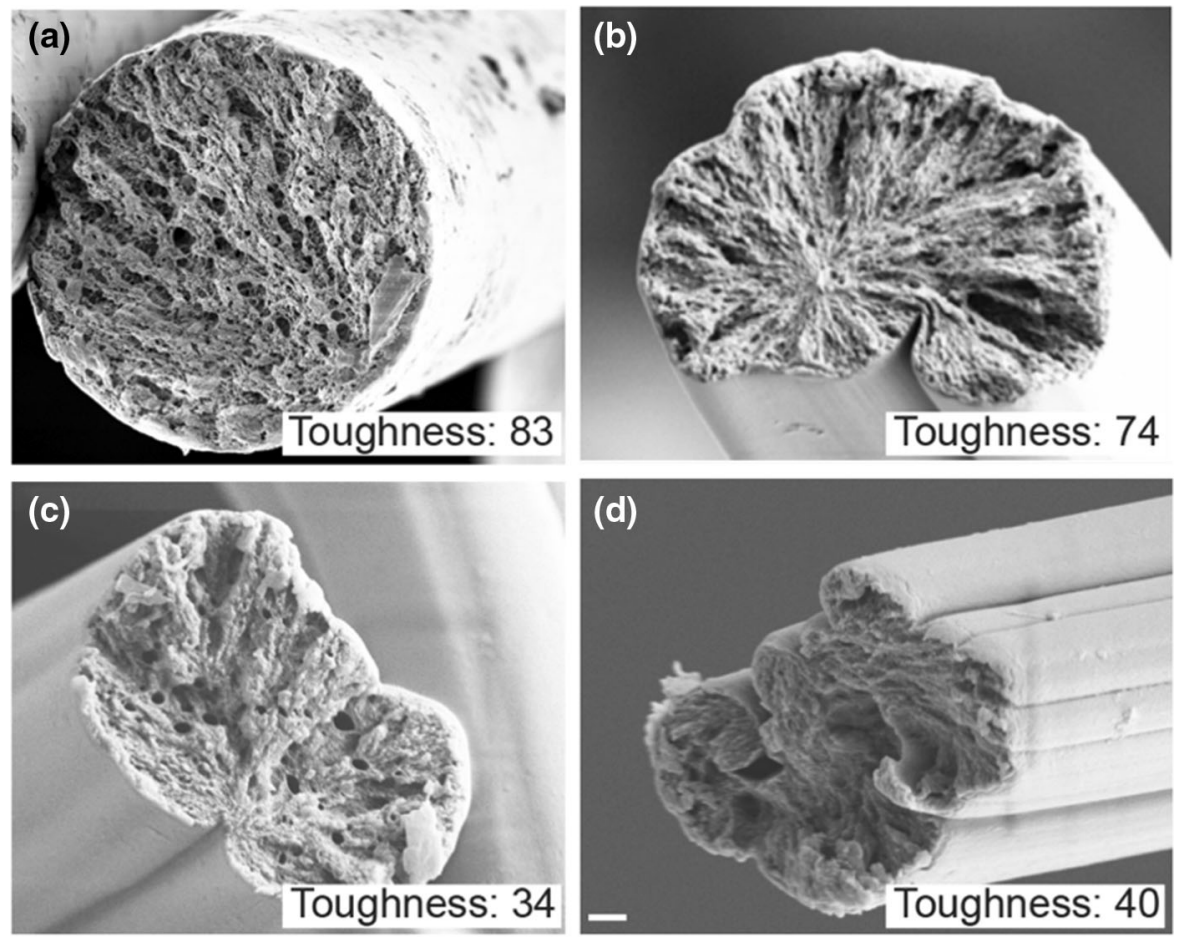

Fig. 7 Comparison of the different fiber morphologies SEM images of a Ioncell /DR10, b Super 3 cord, $\mathbf{c}$ Lenzing ${ }^{\mathrm{TM}} \mathrm{modal}$ \& d Viscose fibers. Scale bar $1 \mu \mathrm{m}$ 
Lenzing $^{\mathrm{TM}}$ modal fibers have shorter and partially clustered crystallites, which leads to a higher lateral strength, and thus prevents fibrillation (Schurz and Lenz 1994b). As a Lyocell type fiber, the Ioncell fiber also tends to fibrillate under wet abrasion. Longer fibrillation treatment increased the number of fibrils along the fiber surface which is reflected in the increase of the fibrillation index with extended treatment time. (Fig. 8a and b).

Since both STG- and HPG-based fibers were produced under similar conditions, orientation is the most dominating factor governing the fibrillation of the regenerated fiber. Owing to the higher total orientation (Fig. S4b) of HPG $13 \mathrm{wt} \%$ DDR10 fiber might show a significantly higher fibrillation index compared to that of STG 13 wt\%_DR12 (Fig. 8b). The well-aligned crystalline region reduces their lateral cohesion, thus, lead to enhanced fibrillation of the HPG-based fibers under mechanical stress (Lim et al. 2003; Mortimer and Peguy 1996). The higher fibrillation tendency of the HPG-based fiber can be explained by the very low amount of hemicelluloses and the long cellulose molecules with a narrow molecular weight distribution with both high amorphous and crystalline orientation, which prevent the formation of lateral cross-links, and thus promote delamination under high shear forces in the swollen state.

\section{Conclusion}

The targeted improvement of the fiber strength of man-made cellulose fibers is crucial for their future use in applications where synthetic fibers currently predominate. Our findings on Ioncell fibers reported in this paper now offer a unique opportunity to simultaneously increase tensile strength and elongation, thus gradually approaching the properties of polyester fibers (Fig. S5b). Sustainably produced fibers with high strength properties can be used in textiles for clothing and various technical applications with long durability. We have demonstrated how fiber strength and especially toughness can be related to structural properties of the fibers, the macromolecular and chemical properties of the pulps used and the aspect ratio of the cylindrical part of the spinneret. Pulp with very low non-cellulosic impurities and a narrow molecular weight distribution (referred to as highpurity pulp) showed excellent spinnability both at a concentration of 13 and $15 \mathrm{wt} \%$ pulp in [DBNH][OAc], although the viscoelasticity of this solution, which is characterized by the complex viscosity, the angular frequency at the COP and the complex moduli at the COP, was outside the optimal spinning window as previously determined. The spinning behavior was improved in particular by the high length-to-diameter ratio of the spinneret capillary, which led to a lower number of breaks induced by the agglomeration of the spinning dope on the outer surface of the spinneret. The toughness of the fiber produced from HPG pulp improved significantly at the
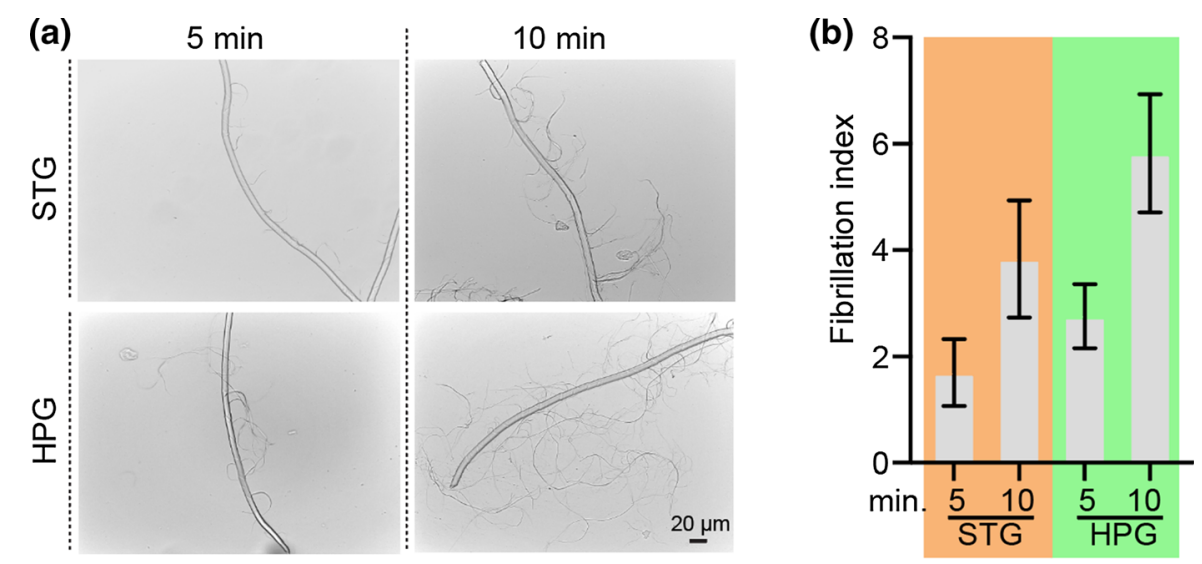

Fig.8 Difference in fibrillation tendency between STG and HPG a fibrillated STG and HPG fibers after 5- and 10-min, b Change in fibrillation index with time (5 and $10 \mathrm{~min}$ ) for STG and HPG. Scale bar $20 \mu \mathrm{m}$ 
target titer for textile fibers of $1.3 \pm 0.2$ dtex regardless of the spinneret geometry due to the presence of a higher fraction of longer molecular chains and the absence of non-cellulosic constituents. The use of a spinneret with a longer cylindrical capillary (L/ $\mathrm{D}=2.0$ ) further improved the HPG-based fiber properties. Fluid dynamic simulation and geometric considerations showed that the longer cylindrical capillary geometry promotes effective molecular alignment with high shear power, which can contribute to high toughness of the fiber. Indeed, the strongest fiber (tenacity $61.4 \mathrm{cN} /$ tex, $14.7 \%$ elongation resulting in a toughness of $83.3 \mathrm{MPa}$ ) was achieved using $13 \mathrm{wt} \%$ cellulose concertation and with a higher spinneret length-to-diameter ratio $(\mathrm{L} / \mathrm{D}=2.0)$ (Fig. S8). Exceptionally, when improving mechanical properties, the degree of orientation, crystal size or crystallinity remained largely unchanged. SANS revealed that a higher tilt angle between crystallites (increased interlinks between crystalline and amorphous domain), a longer periodicity of the lamellar plane and a reduced micro void orientation could contribute to a simultaneous increase in elongation and tensile strength resulting in high toughness fibers. Compared to STG-based fibers, HPG-based fibers showed a significantly higher fibrillation tendency, which correlates with the higher total cellulose orientation and a lower lateral cohesion of the crystallites.

In summary, this is an important milestone in improving the sustainability of the textile industry (as for the first time a closed-loop manufacturing process using only green materials (cellulose) and a green solvent makes it possible to produce textile fibers that achieve hitherto unattained properties previously reserved exclusively for synthetic fibers. We intend to further study the different spinneret geometries to gain more detailed insights into the structure-property relationship of Ioncell fibers.

Acknowledgments This project has received funding from the Academy of Finland (under the project WTF-click-nano), Walter Ahlström foundation, Puunjalostusinsinöörit Säätiö, Tekniikan Edistämissäätiö and FinnCERES. The authors also gratefully acknowledge Nina Pulkkis for preparing the graphical abstract; Nicole Nygren (Aalto University) for her support in fiber testing; Marja Rissanen and Leena Pitkänen for their intellectual support during writing. Additionally, the authors acknowledge the provision of facilities and technical support by Aalto University at OtaNano -Nanomicroscopy Center (AaltoNMC) and D22 instrument at ILL, Dr. Lionel Porcar.
Funding Open access funding provided by Aalto University.

\section{Declaration}

Conflict of interest The authors declare that they have no conflict of interest.

Human and animal rights This research does not contain any experiments with human participants or animals.

Open Access This article is licensed under a Creative Commons Attribution 4.0 International License, which permits use, sharing, adaptation, distribution and reproduction in any medium or format, as long as you give appropriate credit to the original author(s) and the source, provide a link to the Creative Commons licence, and indicate if changes were made. The images or other third party material in this article are included in the article's Creative Commons licence, unless indicated otherwise in a credit line to the material. If material is not included in the article's Creative Commons licence and your intended use is not permitted by statutory regulation or exceeds the permitted use, you will need to obtain permission directly from the copyright holder. To view a copy of this licence, visit http://creativecommons.org/licenses/by/4.0/.

\section{References}

Abihssira-García IS, Park Y, Kiron, V, Olsvik PA (2020) Fluorescent microplastic uptake by immune cells of atlantic salmon (Salmo salar L.). Front Environ Sci. https://doi.org/ $10.3389 /$ fenvs. 2020.560206

Abushammala H, Hettegger H, Bacher M, Korntner P, Potthast A, Rosenau T, Laborie MP (2017) On the mechanism of the unwanted acetylation of polysaccharides by 1,3-dialkylimidazolium acetate ionic liquids: part 2-the impact of lignin on the kinetics of cellulose acetylation. Cellulose 24:2767-2774. https://doi.org/10.1007/s10570-017-1322-X

Acharya S, Rumi SS, Hu Y, Abidi N (2021) Microfibers from synthetic textiles as a major source of microplastics in the environment: a review. Text Res J. https://doi.org/10.1177/ 0040517521991244

Adusumalli RB, Keckes J, Martinschitz KJ, Boesecke P, Weber H, Roeder T, Gindl W (2009) Comparison of molecular orientation and mechanical properties of lyocell fibre tow and staple fibres. Cellulose 16:765-772. https://doi.org/10. 1007/s10570-009-9292-2

Asaadi S, Hummel M, Hellsten S, Härkäsalmi T, Ma Y, Michud A, Sixta H (2016) Renewable high performancefibers from the chemical recycling of cotton waste utilizing an ionic liquid. Chemsuschem 9:3250-3258. https://doi.org/10. 1002/cssc. 201600680

Asaadi S, Hummel M, Ahvenainen P, Gubitosi M, Olsson U, Sixta H (2018a) Structural analysis of Ioncell-F fibres from birch wood. Carbohyd Polym 181:893-901. https://doi. org/10.1016/j.carbpol.2017.11.062

Asaadi S, Kakko T, King AWT, Kilpelainen I, Hummel M, Sixta H (2018b) High-performance acetylated ioncell-F fibers 
with low degree of substitution. ACS Sustain Chem Eng 6:9418-9426. https://doi.org/10.1021/acssuschemeng. $8 \mathrm{~b} 01768$

Bentivoglio G, Roeder T, Fasching M, Buchberger M, Schottenberger H, Sixta H (2006) Cellulose processing with chloride-based ionic liquids. Lenzinger Berichte 86:154-161

Chen X, Zhang Y, Cheng L, Wang H (2009) Rheology of concentrated cellulose solutions in 1-butyl-3-methylimidazolium chloride. J Polym Environ 17:273-279. https:// doi.org/10.1007/s10924-009-0149-4

Dorn S, Wendler F, Meister F, Heinze T (2008) Interactions of ionic liquids with polysaccharides -7 : thermal stability of cellulose in ionic liquids and N-methylmorpholine-N-oxide. Macromol Mater Eng 293:907-913. https://doi.org/10. 1002/mame.200800153

Ebner G, Schiehser S, Potthast A, Rosenau T (2008) Side reaction of cellulose with common 1-alkyl-3-methylimidazolium-based ionic liquids. Tetrahedron Lett 49: 7322-7324. https://doi.org/10.1016/j.tetlet.2008.10.052

Elsayed S, Hellsten S, Guizani C, Witos J, Rissanen M, Rantamäki AH, Sixta H (2020) Recycling of superbase-based ionic liquid solvents for the production of textile-grade regenerated cellulose fibers in the lyocell process. ACS Sustain Chem Eng 8:14217-14227. https://doi.org/10. 1021/acssuschemeng.0c05330

Essel R, Engel L, Carus M, Ahrens RHJT (2015) Sources of Microplastics Relevant to Marine Protection in Germany 64:1219-1226

Fink HP, Weigel P, Purz HJ, Ganster J (2001) Structure formation of regenerated cellulose materials from NMMOsolutions. Prog Polym Sci 26:1473-1524. https://doi.org/ 10.1016/S0079-6700(01)00025-9

The Fiber Year (2019) World survey on textiles \& nonwovens. The Fiber Year GmbH. TOC2019.pdf. https://www. thefiberyear.com. Accessed 19 May 2019

The Fiber Year (2020) World survey on textiles \& nonwovens. The Fiber Year GmbH. TFY2020.pdf. https://www. thefiberyear.com. Accessed 20 June 2020

Goetze K (1964) Developments in the field of high-strength viscose fibers. Oesterreichische Chemiker Zeitung 65:209-218

Goswami P, Blackburn RS, El-Dessouky HM, Taylor J, White P (2009) Effect of sodium hydroxide pre-treatment on the optical and structural properties of lyocell. Eur Polymer J 45:455-465. https://doi.org/10.1016/j.eurpolymj.2008.10. 030

Graessley WW (1980) Polymer chain dimensions and the dependence of viscoelastic properties on concentration, molecular weight and solvent power. Polymer 21:258-262. https://doi.org/10.1016/0032-3861(80)90266-9

Guizani C, Larkiala S, Moriam K, Sawada D, Elsayed S, Rantasalo S, Sixta H (2020) Air gap spinning of a cellulose solution in [DBNH][OAc] ionic liquid with a novel vertically arranged spinning bath to simulate a closed loop operation in the Ioncell ${ }^{\circledR}$ process. J Appl Polym Sci 138:49787. https://doi.org/10.1002/app.49787

Guo S, Li X, Zhao R, Gong Y (2021) Comparison of life cycle assessment between lyocell fiber and viscose fiber in China. Int J Life Cycle Assess. https://doi.org/10.1007/ s11367-021-01916-y
Haslinger S, Hummel M, Anghelescu-Hakala A, Määttänen M, Sixta H (2019) Upcycling of cotton polyester blended textile waste to new man-made cellulose fibers. Waste Manage 97:88-96. https://doi.org/10.1016/j.wasman.2019. 07.040

Hong JH, Ku MK, Ahn Y, Kim HJ, Kim H (2013) Air-gap spinning of cellulose/ionic liquid solution and its characterization. Fibers and Polymers 14:2015-2019. https://doi. org/10.1007/s12221-013-2015-1

Huerta Lwanga E, Gertsen H, Gooren H, Peters P, Salánki T, van der Ploeg M, Geissen V (2016) Microplastics in the terrestrial ecosystem: implications for lumbricus terrestris (Oligochaeta, Lumbricidae). Environ Sci Technol 50:2685-2691. https://doi.org/10.1021/acs.est.5b05478

Hummel M, Michud A, Tanttu M, Asaadi S, Ma Y, Hauru LKJ, Sixta H (2016) Ionic Liquids for the Production of ManMade Cellulosic Fibers: Opportunities and Challenges. In: Rojas OJ (ed) Cellulose chemistry and properties: fibers, nanocelluloses and advanced materials. Springer, Cham

Johnson DL (1969) Compounds dissolved in cyclic amine oxides. Patent number US3447939A. Eastman Kodak Co

Jusner P, Bacher M, Hettegger H, Lê HQ, Potthast A, Sixta H, Rosenau T (2021) On the chemical interactions of the biomass processing agents $\gamma$-valerolactone (GVL) and $\mathrm{N}$-methylmorpholine-N-oxide (NMMO). Green Chem. https://doi.org/10.1039/D1GC01777B

Kotek R (2007) Regenerated cellulose fibers. In: Lewin M (ed) Handbook of fiber chemistry. CRC Press Taylor \& Francis Group, Boca Raton, FL, pp 33487-2742

Krässig H, Kitchen W (1961) Factors influencing tensile properties of cellulose fibers. J Polym Sci 51:123-172. https:// doi.org/10.1002/pol.1961.1205115509

Langan P, Nishiyama Y, Chanzy H (2001) X-ray Structure of mercerized cellulose II at $1 \AA$ resolution. Biomacromol 2:410-416. https://doi.org/10.1021/bm005612q

Laus G, Bentivoglio G, Schottenberger H, Kahlenberg V, Kopacka H, Roeder H, Sixta H (2005) Ionic liquids: current developments, potential and drawbacks for industrial applications. Lenzinger Berichte 84:71-85

Lim KY, Seong YJ, Kim BC (2003) Reduction of fibrillation of Lyocell Fiber with Cellulose-g-Poly(vinyl alcohol) copolymer. Polym J 35:691-696. https://doi.org/10.1295/ polymj.35.691

Ma Y, Stubb J, Kontro I, Nieminen K, Hummel M, Sixta H (2018) Filament spinning of unbleached birch kraft pulps: Effect of pulping intensity on the processability and the fiber properties. Carbohyd Polym 179:45-151. https://doi. org/10.1016/j.carbpol.2017.09.079

Ma Y, Rissanen M, You X, Moriam K, Hummel M, Sixta H (2020) New method for determining the degree of fibrillation of regenerated cellulose fibres. Cellulose 28:31-44. https://doi.org/10.1007/s10570-020-03513-y

Ma K, Jin X, Zheng M, Gao H (2021) Dissolution and functionalization of celluloses using 1,2,3-triazolium ionic liquid. Carbohydrate Polymer Technol Appl 2:100109. https://doi.org/10.1016/j.carpta.2021.100109

McCorsley CC III (1978) Process for shaped cellulose article prepared from a solution containing cellulose dissolved in a tertiary amine N-oxide solvent. Patent number US4246221A. Akzona Inc USA 
Michud A, Hummel M, Sixta H (2016) Influence of process parameters on the structure formation of man-made cellulosic fibers from ionic liquid solution. J Appl Polym Sci 133:30. https://doi.org/10.1002/app.43718

Mortimer SA, Peguy AA (1996) The influence of air-gap conditions on the structure formation of lyocell fibers. J Appl Polym Sci 60:1747-1756. https://doi.org/10.1002/ (sici)1097-4628(19960606)60:103.0.co;2-\#

Murthy NS, Grubb DT (2006) Tilted lamellae in an affinely deformed 3D macrolattice and elliptical features in smallangle scattering. J Polym Sci, Part B: Polym Phys 44:1277-1286. https://doi.org/10.1002/polb.20778

Murthy NS, Grubb DT, Zero K, Nelson CJ, Chen G (1998) Lamellar structure and properties in poly(ethylene terephthalate) fibers. J Appl Polym Sci 70:2527-2538. https://doi.org/10.1002/(SICI)1097-4628(19981219)70: 12\%3c2527::AID-APP27\%3e3.0.CO;2-J

Murthy NS, Grubb DT, Zero K (2000) Structural implications of the elliptical form of small-angle reflections in oriented semicrystalline polymers. Macromolecules 33:1012-1021. https://doi.org/10.1021/ma9911501

Napper IE, Thompson RC (2016) Release of synthetic microplastic plastic fibres from domestic washing machines: effects of fabric type and washing conditions. Mar Pollut Bull 112:39-45. https://doi.org/10.1016/j. marpolbul.2016.09.025

Ramsperger AFRM, Narayana VKB, Gross W, Mohanraj J, Thelakkat M, Greiner A, Laforsch C (2020) Environmental exposure enhances the internalization of microplastic particles into cells. Sci Adv 6:eabd1211. https://doi.org/10. 1126/sciadv.abd1211

Röder T, Moosbauer J, Kliba G, Schlader S, Zuckerstätter G, Sixta H (2009) Comparative chracterization of man-made regenerated cellulose fibres. Lenzinger Berichte 87:98-105

Salvador Cesa F, Turra A, Baruque-Ramos J (2017) Synthetic fibers as microplastics in the marine environment: a review from textile perspective with a focus on domestic washings. Sci Total Environ 598:1116-1129. https://doi.org/10. 1016/j.scitotenv.2017.04.172

Sana SS, Dogiparthi LK, Gangadhar L, Chakravorty A, Abhishek N (2020) Effects of microplastics and nanoplastics on marine environment and human health. Environ Sci Pollut Res 27:44743-44756. https://doi.org/ 10.1007/s11356-020-10573-X

Sawada D, Nishiyama Y, Röder T, Porcar L, Zahra H, Trogen M, Hummel M (2021) Process-dependent nanostructures of regenerated cellulose fibres revealed by small angle neutron scattering. Polymer 218:123510. https://doi.org/ 10.1016/j.polymer.2021.123510

Schurz J, Lenz J (1994a) Investigations on the structure of regenerated cellulose fibers. Macromol Symp 83:273-289. https://doi.org/10.1002/masy.19940830123

Schurz J, Lenz J (1994b) Investigations on the structure of regenerated cellulose fibers; Herrn Professor JaneschitzKriegl zum 70. Geburtstag Mit Den Besten Wünschen Gewidmet 83:273-289. https://doi.org/10.1002/masy. 19940830123

Schurz J, Lenz J, Wrentschur E (1995) Inner surface and void system of regenerated cellulose fibers. Die Angewandte
Makromolekulare Chemie 229:175-184. https://doi.org/ 10.1002/apmc.1995.052290112

Sharma A, Wankhede P, Samant R, Nagarkar S, Thakre S, Kumaraswamy G (2021) Process-induced microstructure in viscose and lyocell regenerated cellulose fibers revealed by SAXS and SEM of acid-etched samples. ACS Appl Polymer Mater 3:2598-2607. https://doi.org/10.1021/ acsapm.1c00204

Sixta H, Michud A, Hauru L, Asaadi S, Ma Y, King AWT, Hummel M (2015) Ioncell-F: a high-strength regenerated cellulose fiber. Nord Pulp Pap Res J 30:43-57. https://doi. org/10.3183/npprj-2015-30-01-p043-057

Sluiter A, Hames B, Scarlata C, Sluiter J, Templeton D, Crocker D (2008) Determination of structural carbohydrates and lignin in biomass, in: Laboratory Analytical Procedure (LAP). National Renewable Energy Laboratory

Swatloski RP, Spear SK, Holbrey JD, Rogers RD (2002) Dissolution of cellulose with ionic liquids. J Am Chem Soc 124:4974-4975. https://doi.org/10.1021/ja025790m

Udomkichdecha W, Chiarakorn S, Potiyaraj P (2002) Relationships Between Fibrillation Behavior of Lyocell Fibers and Their Physical Properties. Text Res J 72:939-943. https://doi.org/10.1177/004051750207201101

Von Bucher HP (1968) Viscose rayon textile fibers. Man-Made Fibers: Sci Technol 2:7-42

Wendler F, Todi LN, Meister F (2012) Thermostability of imidazolium ionic liquids as direct solvents for cellulose. Thermochim Acta 528:76-84. https://doi.org/10.1016/j. tca.2011.11.015

Xu A, Wang F (2020) Carboxylate ionic liquid solvent systems from 2006 to 2020: thermal properties and application in cellulose processing. Green Chem 22:7622-7664. https:// doi.org/10.1039/D0GC02840A

$\mathrm{Xu} \mathrm{A}$, Chen L, Wang J (2018) Functionalized imidazalium carboxylates for enhancing practical applicability in cellulose processing. Macromolecules 51:4158-4166. https:// doi.org/10.1021/acs.macromol.8b00724

Zhang W, Okubayashi S, Bechtold T (2005) Fibrillation tendency of cellulosic fibers. part 1: effects of swelling. Cellulose 12:267-273. https://doi.org/10.1007/s10570-0042786-z

Zhang W, Okubayashi S, Badura W, Bechtold T (2006) Fibrillation tendency of cellulosic fibers, part 6: Effects of treatments with additive polymers. J Appl Polym Sci 101:4140-4147. https://doi.org/10.1002/app.23283

Zhang S, Chen C, Duan C, Hu H, Li H, Li J, Ni Y (2018) Regenerated cellulose by the lyocell process, a brief review of the process and properties. Journal of BioResources 13(2):1-16. https://doi.org/10.15376/biores.13.2.Zhang

Zhang D, Fraser MA, Huang W, Ge C, Wang Y, Zhang C, Guo P (2021) Microplastic pollution in water, sediment, and specific tissues of crayfish (Procambarus clarkii) within two different breeding modes in Jianli, Hubei province. China Environmental Pollution 272:115939. https://doi. org/10.1016/j.envpol.2020.115939

Zhu H, Zhu S, Jia Z, Parvinian S, Li Y, Vaaland O, Li T (2015) Anomalous scaling law of strength and toughness of cellulose nanopaper. PNAS 112:8971-8976. https://doi.org/ 10.1073/pnas.1502870112 
Zikeli S, Firgo H, Eichinger D, Jurkovic R (1992) Process for spinning cellulose fibers with high toughness. Patent number EP0494852A2. Lenzing A-G, Austria

Zubris KAV, Richards BK (2005) Synthetic fibers as an indicator of land application of sludge. Environ Pollut 138:201-211. https://doi.org/10.1016/j.envpol.2005.04. 013
Publisher's Note Springer Nature remains neutral with regard to jurisdictional claims in published maps and institutional affiliations. 